Elsevier required licence: (C) 2016. This manuscript version is made available under the CC-BY-NC-ND 4.0 license http://creativecommons.org/licenses/by-nc-nd/4.0/ 


\title{
A comparative study energy consumption and costs of battery electric vehicle transmissions
}

\author{
Jiageng Ruan ${ }^{1 *}$, Paul Walker ${ }^{1}$, Nong Zhang $^{1}$ \\ 1 University of Technology Sydney, 15 Broadway, Ultimo, NSW 2046, Australia \\ *Corresponding Author, Email Address: Jiageng.Ruan@student.uts.edu.au
}

\begin{abstract}
Despite the long-term benefit of battery electric vehicles (BEVs) to customers and environment, the initial cost and limited driving range present significant barriers for wide spread commercialization. The integration of multi-speed transmissions to BEVs' powertrain systems in place of fixed ratio reduction transmissions is considered as a feasible method to improve powertrain efficiency and extend limited driving range for a fixed battery size. The aim of this paper is to enable the researchers or BEV manufacturers, especially for transmission systems, to estimate whether their products are worthwhile for the customer in terms of the price/performance relationship of others' design solutions. To do so a generic battery electric vehicle is modelled in Matlab/Simulink ${ }^{\circledR}$ to predict motor efficiency and energy consumption for single reduction, two speeds Dual Clutch Transmission (DCT) and simplified Continuous Variable Transmission (CVT) equipped battery electric vehicles. A credible conclusion is gained, through experimental validation of single speed and two speeds DCT scenarios and reasonable assumptions to support the CVT scenario, that both two speeds DCT and simplified CVT improve the overall powertrain efficiency, save battery energy and reduce customer costs. However, each of the configurations has unique cost and energy consumption related trade-offs.
\end{abstract}

Keywords: Transmission, battery electric vehicle, cost analysis, EV, DCT, CVT

\section{Introduction}

Due to outstanding dynamic performance of electric motors and the cost containment required for battery electric vehicles (BEVs), fixed ratio single reduction (SR) transmissions are applied on most BEVs rather than multi-gear transmission, e.g. VW e-Golf, Nissan Leaf, BYD e6 and even Tesla Model S. It is very true that electric motors have a very wide operating range and higher efficiency power source comparing to internal combustion engine (ICE), but it doesn't mean that electric motors are equally efficient at all driving speeds and torques. In fact there is a $30 \%$ efficiency variation through the range of actual driving conditions for daily-use to peak efficiency regions, typically from $65 \%$ to $95 \%$ [1]. However, the ratio of SR on BEVs must inevitably be designed as a trade-off between the longer driving range and satisfactory dynamic performance. Thus, the designed fixed ratio is selected at the expense of economy performance.

With the ability of $100 \%$ torque delivery from standing start, wide speed range and excellent dynamic adjustable ability of motor, the requirements for transmission system design on EVs are much simpler than that for ICE vehicles. Many people 
work into adding multi-speed transmissions to BEVs' powertrain to improve motor operating efficiency and enhance driving performance, e.g. It has been proved that multi-speed gearbox can not only improve the overall drivability and motor efficiency, but also to downsize the battery and motor [2,3]. And a simple and simulation based conclusion was presented that 2, 3, 4-speed gearboxes and continuous variable transmission (CVT) improve the overall energy consumption 5\%-12\% depends on driving cycles [4]. A energy consumption comparison of BEV with 1-2 speed gearboxes, half/full toroid CVT and infinity variable transmission (IVT) showed [5] that different transmissions have a 2\%-20\% energy efficiency improvement depending on the selected driving cycles in simulation, which includes regenerative braking. An optimized two speed transmission was integrated into an electric delivery van [6] to reduce acceleration time and energy consumption. The effects of adding a two-speed AMT to BEVs and a similar system was tested on a pure electric bus $[7,8]$. These make up a handful of the available literature that has evaluated the improved economy of adding multispeed transmissions to BEVs.

A plethora of similar papers can be founded. However, economy performance is just one of the key factors that need to be considered during vehicle design. Driving comfort and manufacturing cost deserve careful attention as well. Some limitations of the papers above are:

1. The lack of the analysis that if the energy saved by adding multi-speed transmissions to BEVs will cover the additional manufacturing cost.

2. The lack of the analysing of each transmission's characteristics. Not all the existing transmissions are suitable for BEVs at the point of view of keeping the original advantages of BEV. For instance, Manual Transmission and Automated Manual Transmission may be not suitable for small passenger BEVs due to the inevitable torque interrupting $[9,10]$, although it is efficient.

3. The lack of the shifting schedules optimization for transmission on BEVs. The characteristics of electric motor and ICE are totally different. It is necessary to design a special shifting map for transmission on BEVs to optimise motor performance.

4. The lack of the experimental validation of the hypotheses demonstrated in plenty simulation results. The improvements in simulation may be eliminated in bench testing as various losses that were not included in simulations compound. A convincing conclusion depends on the credibility of the experiments.

In this paper, a two speeds DCT and simplified CVT (without torque converter) are applied in BEV models to boost motor efficiency and reduce energy consumption, whilst maintaining dynamic performance and shifting without torque interrupt. Through gear ratio design and shifting schedule optimization, higher motor efficiency and less energy consumption can be achieved.

Based on the achievements and limitations in previous work, a comprehensive analysis of multi-speed transmission selection process for BEVs is presented in this paper in following parts:

1. Comparison of the mechanical layouts of SR, two speeds DCT and CVT without torque converter. 
2. Gear ratios design for SR, two speed DCT and CVT based on the motor characteristics and vehicle performance requirements;

3. Shifting schedule optimization for two speeds DCT and CVT without torque converter;

4. Simulation results comparison of motor efficiency and energy consumption in urban and highway driving cycles;

5. Bench testing for SR and two speeds DCT in urban and highway driving cycles. Comparison of the motor efficiency and energy consuming of each scenario;

6. The relative selling price of different transmissions based BEVs are calculated. The cost saved in manufacturing, particular driving range and lifetime mileage are presented based on experiment data;

7. Paper is summarized and conclusions are drawn;

\section{Alternative transmission configurations}

\subsection{Fixed ratio single reduction BEV powertrain}

The first generation modern electric vehicles (EVs) are fitted with fixed ratio transmissions as a result of the enhanced capabilities of the electric machine over ICEs. Such vehicles were able to attain a satisfying driving experience whilst offering an acceptable price. Fig.1 demonstrates a typical single speed powertrain including one fixed ratio and one final drive ratio. Additionally, as the motor has the capability to reverse rotation, the reverse shaft is eliminated in all EVs.

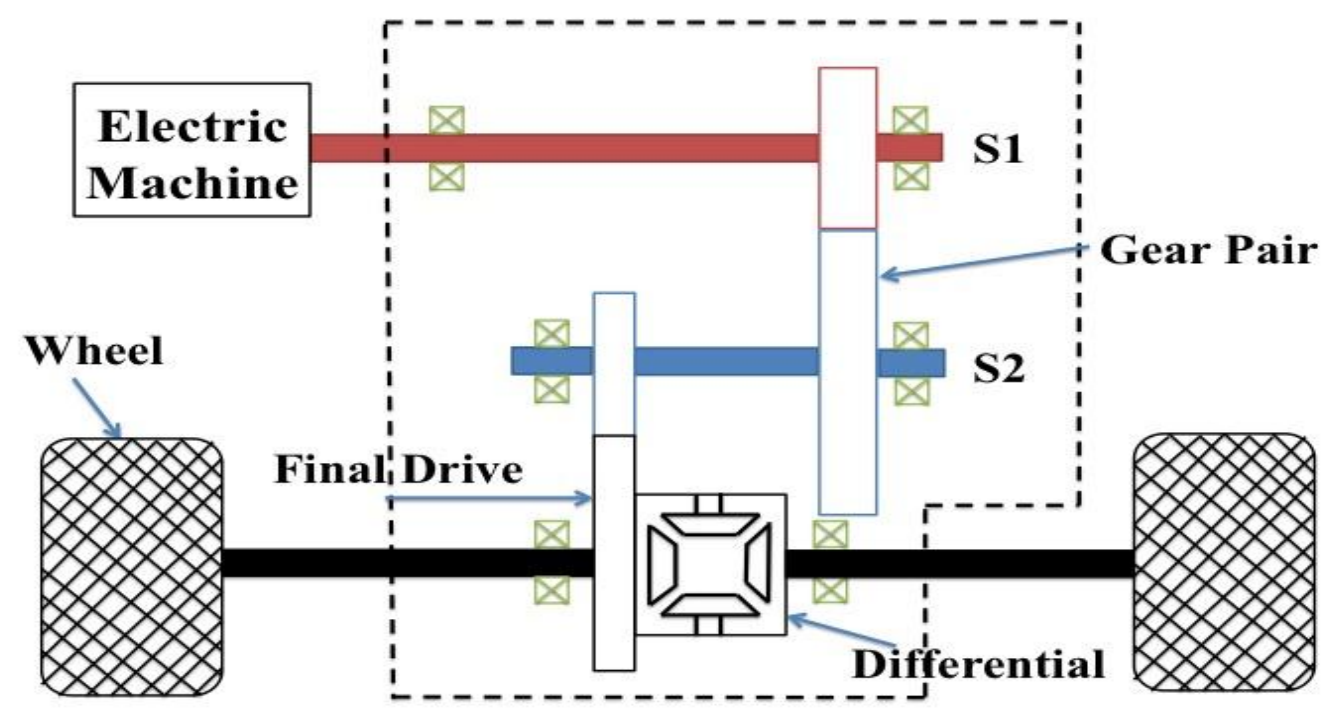

Figure 1 Single speed reduction in BEV powertrain

\subsection{Two Speeds DCT powertrain}

DCT has the ability to transfer torque from one clutch to another with little interrupting traction, thanks to controlling slippage of clutches. Two clutches engage alternatively and one of them will pre-engage before the other one disengage to 
eliminate torque interruption during shifting [11]. The heart of two speed DCT model design is the two clutches have a common drum attached to the input shaft from the motor, and the friction plates are independently connected to 1st and 2nd gear respectively. Thus, synchronizer will be removed from this DCT [12,13]. Analysis and modelling of transit shift situation in two speed DCT equipped EV is proposed by[14]. Based on excellent output torque characteristics on starting period and an economy performance oriented shifting schedule, 2 speeds DCT will be validated against several alternative driving cycles in this paper.

Fig.2 presents the structure of a front wheel drive two speeds DCT based powertrain for BEVs. With a common drum attached to the input shaft of motor, the friction plates of two clutches are connected to the first and second gears directly. The uniqueness of this two speed DCT powertrain is taking advantage of seamless clutch to clutch shifting, and with only two speeds added the complexity for the synchroniser and its control is eliminated. Therefore, gear shifting is realized through dual clutch control only. The clutches are denoted with $\mathrm{C} 1$ and C2. S1 \& S2 are the solid and hollow input shafts; S3 is the output shaft of DCT.

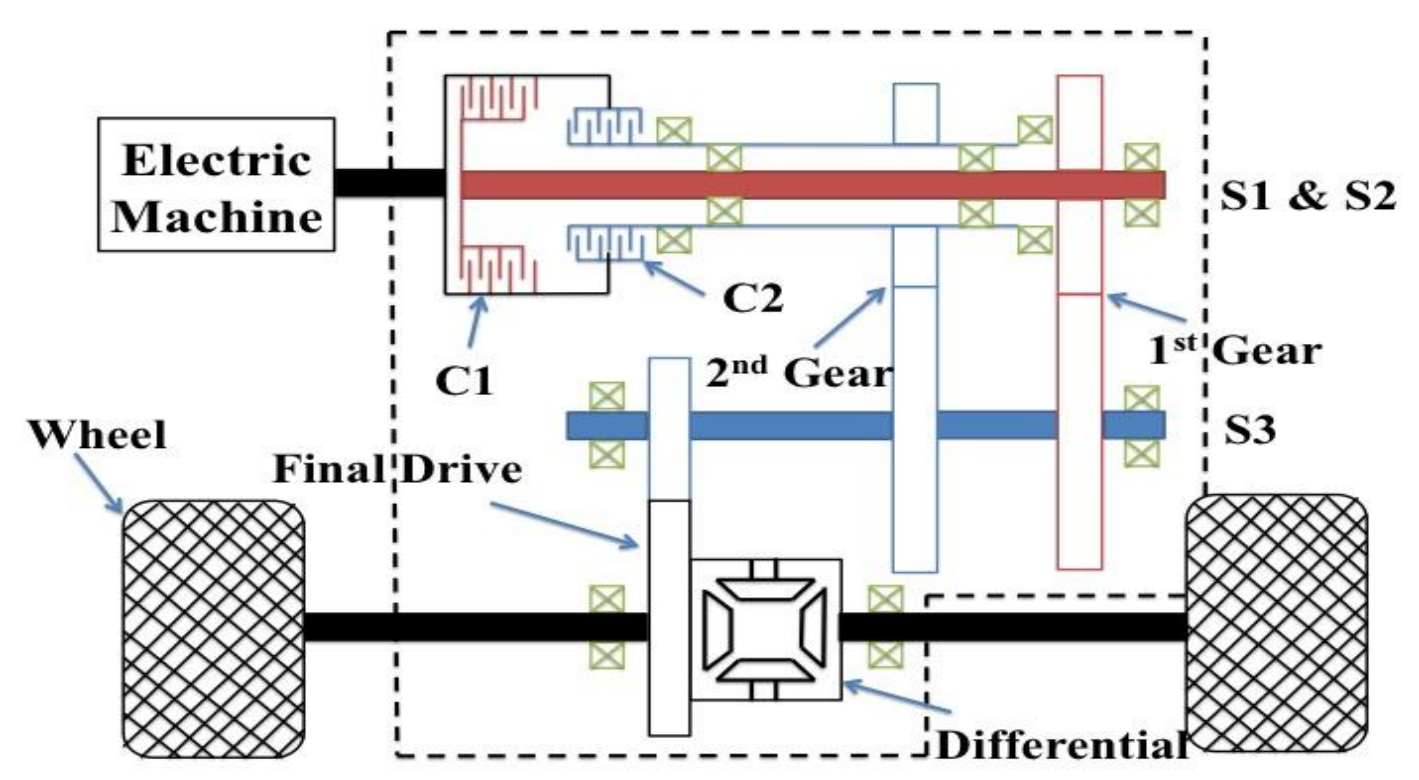

With an additional gear pair, the most significant impact is the increased losses in transmission through clutches, gear mesh and etc. Impactions of efficiency of different components in driveline are:

2. Total loss, including plate friction loss, lubricant viscous loss, gear mesh loss and et al. in first gear: $7 \%$ (Experiment testing result)

3. Total loss, including plate friction loss, lubricant viscous loss, gear mesh loss and et al. in second gear: 5\% (Experiment testing result) 
141 CVT has the ability to adjust gear ratios without interruption of the power flow and an infinite number of ratios (between the minimum and maximum value) are possible. The basic configuration of CVT comprises two variable diameter pulleys kept at a fixed distance apart and connected by a power-transmitting device, e.g. belt or chain. One of the sheaves on each pulley is movable. The belt/chain can undergo both radial and tangential motions depending on the torque loading conditions and the axial forces on the pulleys. This consequently causes continuous variations in the transmission ratio to keep ICE or motor runs around most efficient area [16]. Due to the mechanical layout and the need of torque converter to work with ICE vehicles, the efficiency of CVT is typically lower than that of SR system, and inevitability suffer from poor speed response [17-19], particularly at launch [20]. The ratio coverage of new generation CVTs from Jatco ${ }^{\circledR}$ reaches 7 , world's top level, which means the maximum torque amplifying ratio is 7 times as the minimum one, e.g. 0.4-2.8. The torque and rotation transferred from driving pulley to driven pulley depends on the clamping force between melt belt and conical surface of pulley. For a given coefficient of friction, the required minimum clamping force increases in a linear fashion as torque amplifying ratio increases. Therefore, adjustable clamping force and movable pulleys need additional hydraulic system, which reduces the efficiency of integrated transmission system.

The key to CVTs lies in its simple yet effective belt-pulley design. The transmission ratio between the motor and driven wheels varies in a smooth manner in relation to the variable axial gap between the pulleys. Considering the advantage of excellent motor dynamic performance, e.g. 100\% torque output ability from stall, accurate and fast adjusting ability and no limitation of minimum speed for steady running, torque converter is not an essential component for EVs, which is vital to CVT in ICE vehicles aiming at smooth launching and isolating vibration from engine. However, CVT does not exhibit a higher overall efficiency than other automatic transmissions, because the driving torque is transferred by means of contact and friction. The primary efficiency loss in an integrated CVT system comprise of hydraulic pump power loss, variator torque loss and torque converter power loss. Nevertheless, from the beginning of $21^{\text {st }}$ century to $2010 \mathrm{~s}$, lots of manoeuvres have been taken to overcome it. The overall efficiency was improved from less than $70 \%$ to more than $85 \%$ during the past decade [21-23]. Firstly, the axial displacement of moveable pulleys is implemented by two independent servo-electromechanical actuation system, instead of hydraulic-mechanical pump, which significantly reduces the power loss. The promoted structure, in this paper, is an optimized version based on the principles and experimental results from published literatures[21]. Then, restructured variator control circuit and optimized belt pressure control strategy help further increase the overall efficiency [22]. Another even more important improvement is that torque converter is not a necessary part in BEVs' powertrain anymore and the ratio range could be narrow, thanks to the outstanding motor characteristics. Therefore, a lighter and more compact CVT is possible for BEVs. Moreover, an infinite number of transmission ratios help motor to keep running at its optimum speed all the time. Thus, any increase in losses through the CVT, i.e. drag or control system, can be compensated for through improved use of the motor leading to an improvement of overall powertrain efficiency. 
In this study, efficiency improved and structure simplified CVT schematic is used and presented in Fig.3:

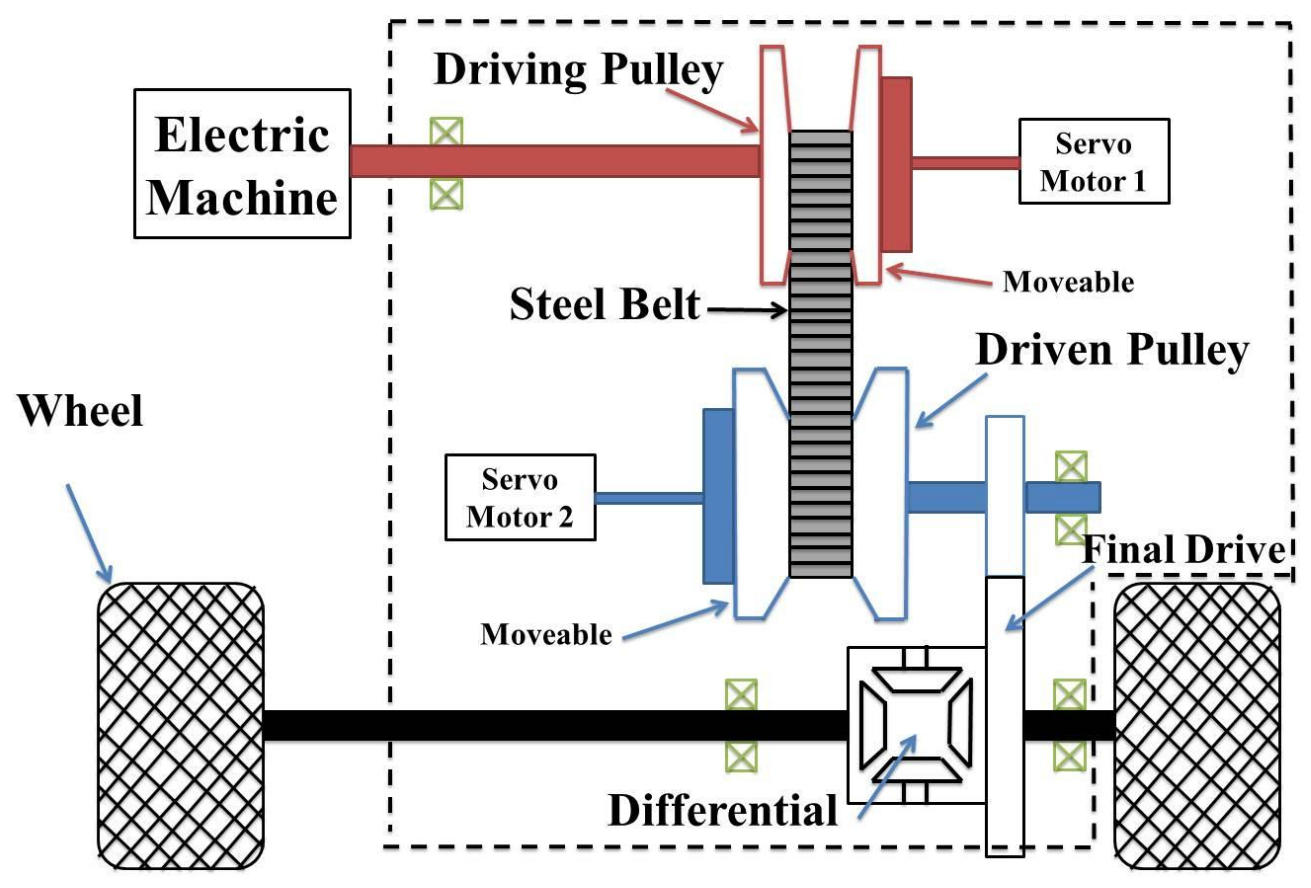

Figure 3 Continuously variable transmission with servo-electromechanical actuation system

The main benefits of using two speeds DCT or CVT without torque converter powertrain in BEVs are:

1. Improved motor efficiency over the vehicle driving range;

2. Decoupled top speed and acceleration capabilities.

200 The disadvantages include:

1. Increased weight from additional components;

2. Poorer transmission efficiency;

3. Additional manufacturing costs.

Both the advantages and disadvantages need to be considered to evaluate the selected multi-speed transmissions for BEVs.

\section{Target vehicle performance characteristics}

Target performance and vehicle specifications used in simulation are provided in 208 Table $1 \& 2$. 


\begin{tabular}{|c|c|}
\hline Performance specification & Nominal result \\
\hline Acceleration 0-100km/h & $15 \mathrm{~s}$ \\
\hline Top speed @ 6\% grade & $150 \mathrm{~km} / \mathrm{h}$ \\
\hline Range @ 60km/h & $150 \mathrm{~km}$ \\
\hline Grade & $30 \%$ \\
\hline
\end{tabular}

Table 2: Vehicle specifications

\begin{tabular}{|c|c|c|c|}
\hline Parameter & Description & Value & Units \\
\hline $\mathrm{m}$ & Vehicle mass (Incl. Battery) & 1760 & $\mathrm{~kg}$ \\
\hline $\mathrm{r}$ & Tyre radius & 0.3125 & $\mathrm{~m}$ \\
\hline$i_{g}$ & Gear ratio & & - \\
\hline $\mathrm{C}_{\mathrm{R}}$ & Coefficient of rolling resistance & 0.016 & - \\
\hline $\mathrm{g}$ & Gravitation Acceleration & 9.81 & $\mathrm{~m} / \mathrm{s}^{2}$ \\
\hline$\varphi$ & Road incline & - & $\%$ \\
\hline $\mathrm{C}_{\mathrm{D}}$ & Drag coefficient & 0.28 & $\mathrm{~m}$ \\
\hline $\mathrm{A}$ & Vehicle frontal area & 2.2 & $\mathrm{~m} / \mathrm{s}$ \\
\hline $\mathrm{u}$ & Vehicle speed & - & $\mathrm{Nm}$ \\
\hline$T_{\text {peak }} / T_{\text {rate }}$ & Motor Peak/Rate output torque & $300 / 150$ & $\mathrm{Kh}$ \\
\hline$P_{\text {peak }} / P_{\text {rate }}$ & Motor Peak/Rate output power & $125 / 45$ & $\mathrm{rm}$ \\
\hline $\mathrm{n}_{\text {max }}$ & Max Motor Speed & 8000 & 380 \\
\hline Bat $_{\mathrm{v}}$ & Battery Voltage & 72 & $\mathrm{~N}$ \\
\hline $\mathrm{B}$ & Battery Capacity & & \\
\hline
\end{tabular}

Table 3: Assumed vehicle data in simulation

\begin{tabular}{|c|c|c|}
\hline Parameter & Description & Value \\
\hline$\eta_{\text {single }}$ & Single Reducer efficiency & 0.95 \\
\hline$\eta_{c v t}$ & CVT efficiency (No Torque Converter) & $0.9-0.95$ \\
\hline
\end{tabular}




\begin{tabular}{|l|l|c|}
\hline$\eta_{\text {differential }}$ & Differential efficiency & 0.95 \\
\hline
\end{tabular}

\section{3}

214

\section{Transmission gear ratio design}

To meet the vehicle performance requirement presented in table 1, the gear ratios of $S R$, two-speed DCT and simplified CVT are carefully designed in three aspects, i.e. top speed, max grade and acceleration time. To select proper gear ratios for SR, two speeds DCT and simplified CVT, restrictive conditions, i.e. Eq.A2, Eq.A3 and Eq.A8 in appendices should be observed. The ratio requirement for top speed is in conflict with that for grade climbing and acceleration time in SR ratio design. It cannot be attained in one single ratio. It means an inevitable dynamic performance trade-off for SR transmission. For the two speeds DCT, $1^{\text {st }}$ gear is selected for accelerating and climbing, meets requirement in equation (3) and (8); $2^{\text {nd }}$ gear is used to cruise at high speed, meets requirement in equation (2). The designed ratio coverage for CVT scenario is $5(2.5 / 0.5)$. Such value for mainstream and leading products are 6 and 7 , which means the special designed CVT in this study is lighter, cheaper and more compact.

The ratios of two speeds DCT are taken from $2^{\text {nd }}$ and $3^{\text {rd }}$ gear in DQ250, which is a six speeds wet clutch DCT used in VW Golf range. As the selected ratio for this study is limited to the designed system of the powertrain test rig, to achieve a creditable result with minimum cost, the ratio of SR is selected as same to the $1^{\text {st }}$ gear ratio in two speeds DCT. This ratio supplies a fast acceleration time, better grade ability, but, a reduced top speed.

The following table lists all the ratios for SR, two speeds DCT and CVT (Incl. final drive):

Table 4: Gear ratios in different transmission systems

\begin{tabular}{|l|c|c|c|c|c|}
\hline \multicolumn{2}{|c|}{ SR } & \multicolumn{2}{c|}{ Two speed DCT } & \multicolumn{2}{c|}{ CVT } \\
\hline \multirow{3}{*}{2.15} & \multirow{2}{*}{ Fianl:3.93 } & $1^{\text {st }}: 2.15$ & Fianl:3.93 & $\begin{array}{c}\text { Pulley: } \\
0.5 \sim 2.5\end{array}$ & Final $: 4$ \\
& & $2^{\text {nd }}: 1.46$ & & & \\
\hline
\end{tabular}

\section{Shifting schedules for two speed DCT and CVT}

\subsection{Two Speed DCT shifting schedule}

Economy shift schedule design for a two speed DCT drivetrain is based on the motor efficiency map (Fig.4) through calculating motor operating efficiency curve of two gears with speed varying at constant throttle [24]. The intersection point of these two curves is the shifting point for this given vehicle speed and input throttle. Fig.6 (a) 
shows the intersection points of efficiency curve for $1^{\text {st }}$ and $2^{\text {nd }}$ gear at particular throttle and speed. On the right side of intersection points, the efficiency of motor operating in $2^{\text {nd }}$ gear is higher than that in $1^{\text {st }}$ gear. To achieve a more accurate and smoother shifting curve, it is necessary to provide more efficiency crossing points at different throttle opening positions, as shown in 6 (b). With the speed of gear shifting and corresponding throttle opening, economy oriented shifting schedule for two speeds DCT is achieved in 6(c). To avoid gear hunting, i.e. unnecessary and repeated gear shifting, a buffer zone is introduced to the gap between up and down shifting curve.

$$
A_{n}=\frac{v_{n} \uparrow-v_{n+1} \downarrow}{v_{n} \uparrow}
$$

253

254

255

256

257

Where, $v_{n} \uparrow$ is the upshift speed threshold from gear (n) to gear $(\mathrm{n}+1), v_{n+1} \downarrow$ is the downshift speed threshold. $A_{n}$ is usually selected between $0.4 \sim 0.45$ [25]. The optimized downshift schedule can be modified based on obtained upshift schedule as Fig.4 (d):

$$
v_{n+1} \downarrow=(1-0.4) v_{n} \uparrow
$$

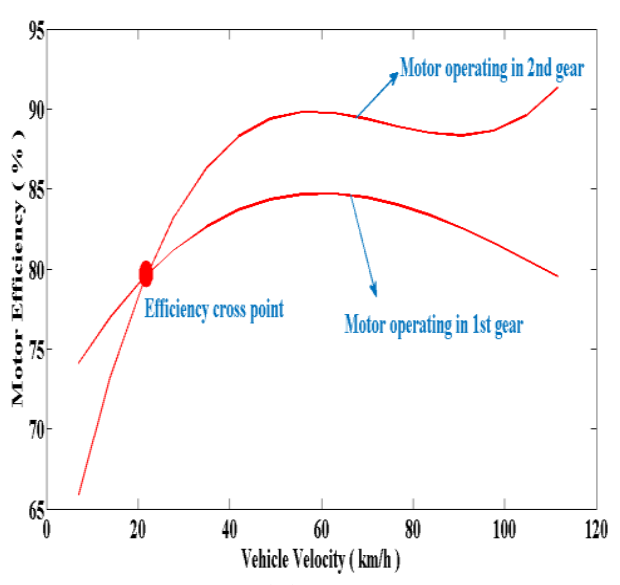

(a)

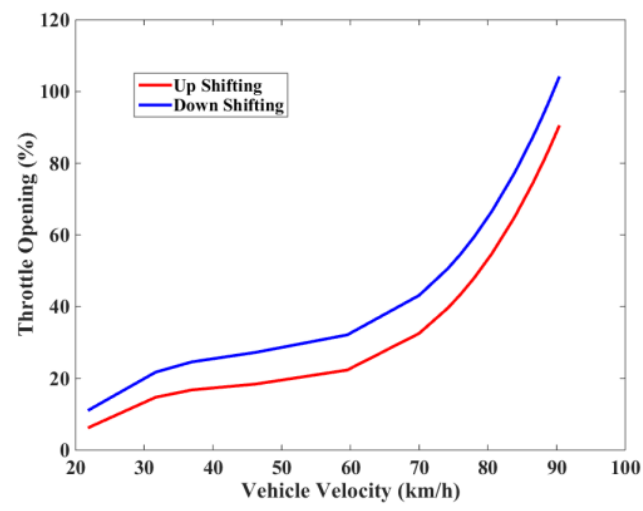

(c)

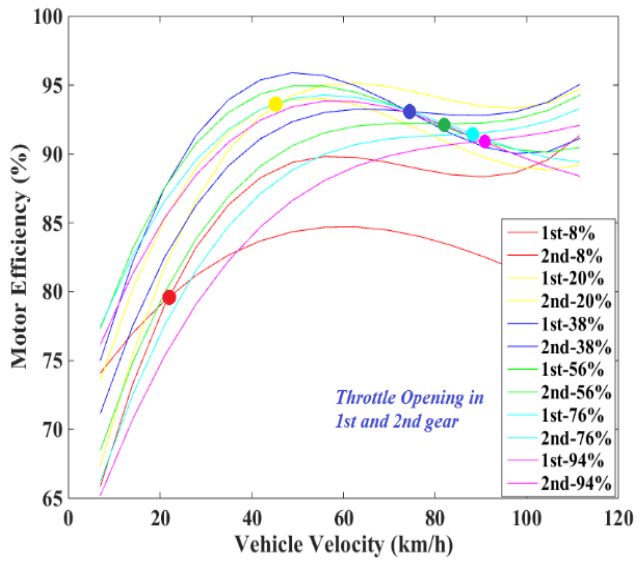

(b)

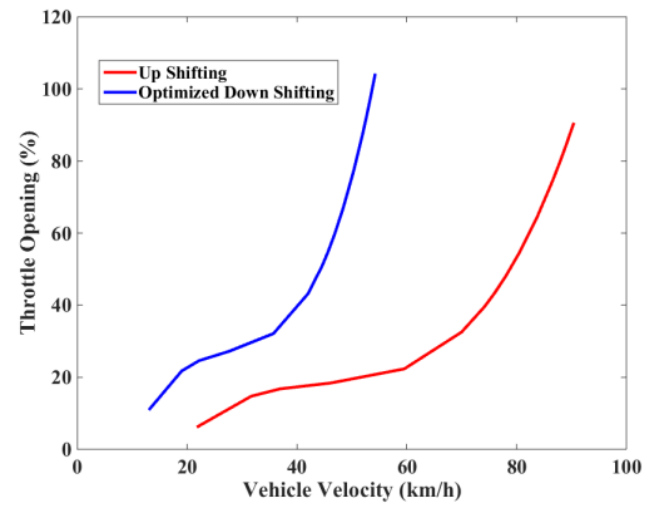

(d)

Figure 4 (a) Economy shifting point selection sample (b) All shifting points at different throttle opening (c) two speeds DCT shifting schedule (d) Optimized shifting schedule 
The ratios of CVT can vary continuously, thus, an infinite number of gear ratios are available between the limitations. For certain vehicle speed and throttle pedal position, the motor speed can continuously vary, according to the selected gear ratio in shifting schedule. Therefore, the most economic gear ratio at particular vehicle speed and throttle position can be determined, by comparing the motor efficiency at such speed with different gear ratio By this analogy, all the economy performance oriented shifting point at particular speed and throttle position can be achieved. The step length of selecting points in available gear ratio coverage is 0.1 . For instance, with $60 \mathrm{~km} / \mathrm{h}$ vehicle speed and $40 \%$ distance of pedal travel, 1.7 is the gear ratio can help motor work in the most efficient area. Part of speed and pedal position based CVT ratios are presented in table 5.

Table 5: CVT ratio calculation data

\begin{tabular}{|c|c|c|c|c|c|c|c|c|c|c|}
\hline $\begin{array}{c}\text { Throttle Pedal } \\
\text { Gear Ratio Position }\end{array}$ & \multirow{2}{*}{0.1} & 0.2 & 0.3 & 0.4 & 0.5 & 0.6 & 0.7 & 0.7 & 0.9 & 1 \\
\cline { 1 - 6 } Speed (km/h) & & & & & & & & & & \\
\hline 10 & 2.5 & 2.5 & 2.5 & 2.5 & 2.5 & 2.5 & 2.5 & 2.5 & 2.5 & 2.5 \\
\hline 30 & 2.3 & 2.3 & 2.3 & 2.5 & 2.5 & 2.5 & 2.5 & 2.5 & 2.5 & 2.5 \\
\hline 50 & 1.2 & 1.4 & 1.4 & 2 & 2 & 2 & 1.9 & 1.8 & 1.9 & 1.9 \\
\hline 70 & 1 & 1 & 1 & 1.3 & 1.4 & 1.4 & 1.4 & 1.4 & 1.4 & 1.4 \\
\hline 90 & 0.8 & 0.8 & 0.8 & 1 & 1.1 & 1.1 & 1.1 & 1.1 & 1.1 & 1.1 \\
\hline 110 & 0.6 & 0.6 & 0.6 & 0.9 & 0.9 & 0.9 & 0.92 & 0.9 & 0.9 & 0.9 \\
\hline 130 & 0.5 & 0.5 & 0.5 & 0.7 & 0.7 & 0.8 & 0.8 & 0.7 & 0.7 & 0.7 \\
\hline
\end{tabular}

\section{Simulation}

The model adopted for the estimation of the energy efficiency along driving schedules is, for reasons of computational efficiency, a backward-facing model shown in Fig.5. It calculates the required electric motor torque, starting from the velocity profile of the assigned driving schedule. Then it predicts the power dissipation within the battery, the electric motor and inverter, the gearbox (separated into lay shaft and differential losses), the tires, the brakes losses and recovery. 


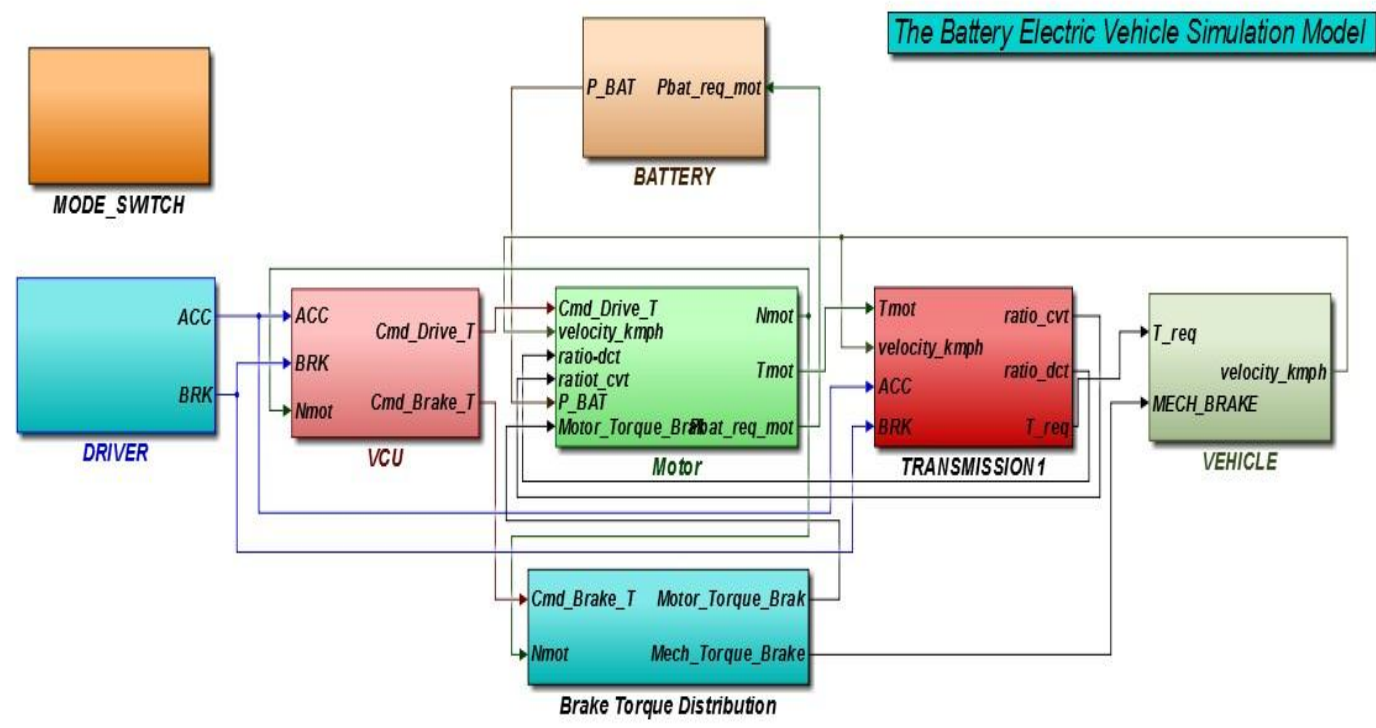

289 Driving performance of BEV with three different transmission configurations is 290 simulated in the Urban Driving Cycle (ECE-15), Highway Fuel Economic Test Cycle 291 (HWFET) and California Unified Cycle, also referred to LA92. Each of these three 292 cycles have strikingly different speed, acceleration, and braking conditions and should 293 therefore provide a reasonable comparison of driving conditions.

\subsection{Economy Performance}

The primary barrier for the commercial popularization of CVT was the relative higher manufacturing cost and lower efficiency, comparing to automatic transmission, in the early days. For a traditional early version CVT powertrain, more than $30 \%$ of input power is wasted by internal hydraulic and mechanical components, i.e. hydraulic pump, torque converter, direction gear sets, friction between belt and variator accounts for about 14\%, 6\%, 3\% and 10\% respectively [22], which is shown in Fig.6.

301 The efficiency of torque converter increases proportionally to output/input speed 302 ratios from zero at stall to $100 \%$ when the turbine and impeller locked together [26].. 


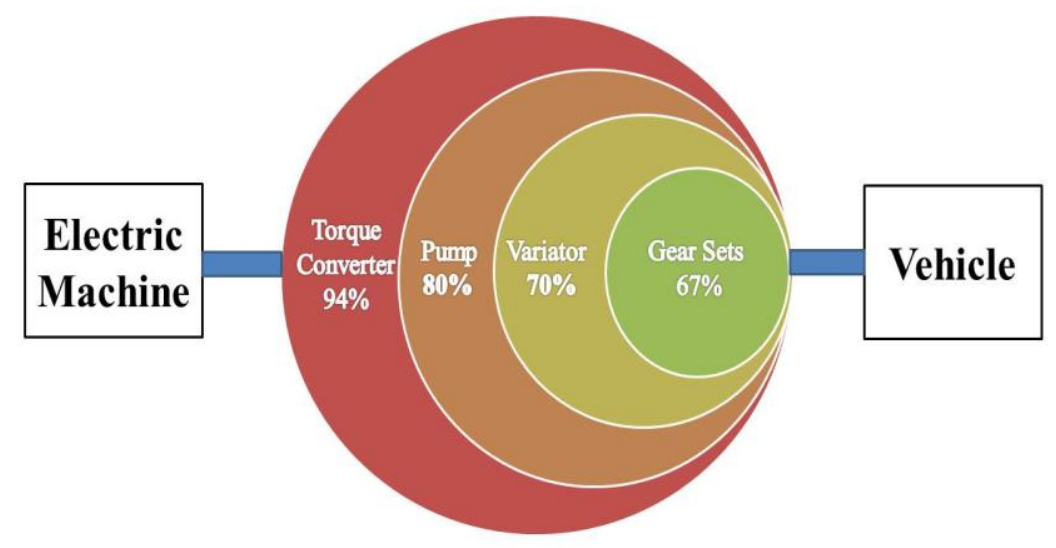

Figure 6: Power loss in each component for a conventional CVT

305 However, CVT offers a great potential for the efficiency improvement by introducing the electrified variator control system and optimized belt pressure control strategy, which are validated by both of simulation and experiment. An load-dependent efficiency improvement for actuators from $25 \%$ to $50 \%$ can be achieved by using servo-electromechanical mechanism, inside of the inefficient hydraulic ones, and optimizing melt belt push force control strategy[21,22]; Additionally, a 2.7\% efficiency benefit can be expected by restructuring the direction gear sets [22]. Furthermore, the eliminated power loss by removing torque converter in this electrified drivetrain will make CVT more competitive. At last, the overall CVT efficiency, according to different load conditions, can be boosted to $83 \%-89 \%$ from less than $70 \%$ in early models.

An input torque and speed ratio-joint dependent Simulink ${ }^{\circledR}$ model is established to precisely predict CVT efficiency in this paper [27].The bottom four dotted curves, in the Fig.8, stand for the power loss in each CVT component at $1500 \mathrm{rpm}$ input speed. The wasted power has already been reduced by above mentioned methods, i.e. electrified actuator, optimized belt pressure, restructured pressure control circuit and gear set. The reason why the last bottom dotted curve-variator power loss almost keeping constant is that the efficiency of variator is mostly determined by the speed ratio of driven/driving pulleys, rather than the input torque. The varying efficiency range of actuators (Pulleys), according to speed ratio, is represented by the top red solid curve. A conspicuous monotonic increase could be found in the influence of input torque to the first three components loss. Then, the torque and speed ratiodependent system efficiency at particular rotation speed can be expressed as equation set (3):

$$
\left\{\begin{array}{c}
e_{\text {torque }}=\left(1-\frac{\sum P_{\text {loss }}}{\frac{T n}{9550}}\right) \\
e_{\text {speedratio }}=f(\text { ratio }) \\
e_{c v t}=e_{\text {torque }} * e_{\text {speedratio }}
\end{array}\right.
$$




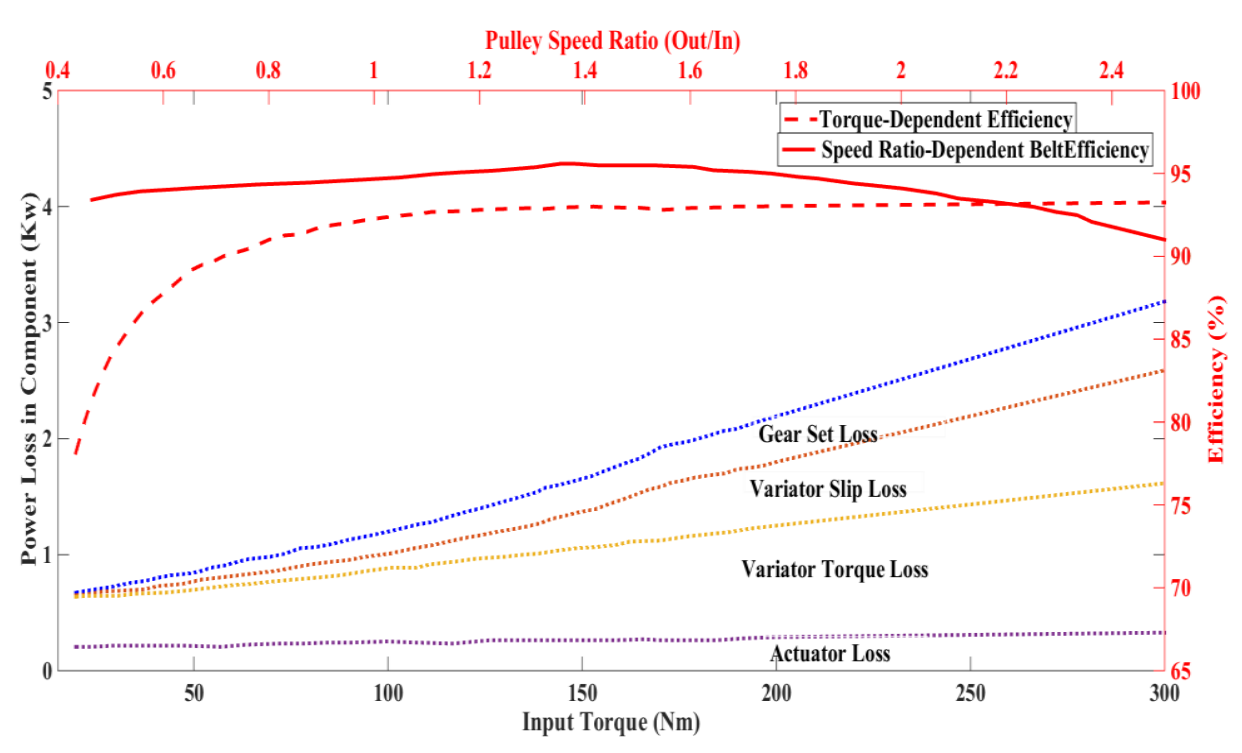

Figure 7: Component efficiency and power loss in CVT

333 The absence of torque converter eliminates power loss and improves dynamic performance in transmission system. However, without the help of torque amplification function of converter, the demanded motor torque will be higher at the same torque requirement at the wheel, which usually leads to an inefficient motor working area, especially for the low speed. As we can see from the first column in the table 6, motor works a little bit more efficiently, no matter in city or highway driving cycles, with the help of torque converter. However, this advantage of traditional CVT system is offset by the improved efficiency in CVT by taking out torque converter, comparing column $2 \& 3$. Thus, at viewpoint of overall efficiency of integrated powertrain system, the simplified CVT has a better economy performance in all driving conditions.

344 Table 6: Simulation results for CVT on BEVs with / without Torque Converter

\begin{tabular}{|c|c|c|c|c|}
\hline & $\begin{array}{c}\text { Motor } \\
\text { Efficiency }\end{array}$ & $\begin{array}{c}\text { Simplified } \\
\text { CVT } \\
\text { Efficiency }\end{array}$ & $\begin{array}{c}\text { CVT (Incl. Converter) } \\
\text { Efficiency }\end{array}$ & $\begin{array}{c}\text { Total } \\
\text { Efficiency }\end{array}$ \\
\hline $\boldsymbol{E} \boldsymbol{C} \boldsymbol{E}$ & & & \\
\hline Simplified CVT & $83.57 \%$ & $74.18 \%$ & N/A & $61.99 \%$ \\
\hline CVT(Incl. Converter) & $82.06 \%$ & N/A & $70.55 \%$ & $57.89 \%$ \\
\hline LA-92 & $82.70 \%$ & $78.86 \%$ & $65.22 \%$ \\
\hline Simplified CVT & $82.93 \%$ & N/A & $62.69 \%$ \\
\hline CVT(Incl. Converter) & & $74.69 \%$ & \\
\hline
\end{tabular}




\begin{tabular}{|lcccc|}
\hline Simplified CVT & $88.88 \%$ & $83.57 \%$ & N/A & $74.28 \%$ \\
\hline CVT(Incl. Converter) & $89.10 \%$ & N/A & $80.89 \%$ & $72.07 \%$ \\
\hline
\end{tabular}

345 Figure 11 (b), (d), (f) show the motor operating regions using each of the three 346 transmissions, namely SR, two speeds DCT and simplified CVT, separately in 347 different driving cycles. Due to the gear ratio selected in the SR being a trade-off 348 between economy and dynamic performance, the motor inevitably run at high speedlow torque and low speed-high torque areas, which usually leads to lower efficiency. Two speeds DCT are more flexible than SR when selecting a proper ratio to meet the driving requirement. With the help of continuous variable gear ratios and economy shifting schedule, motor save more energy and has the best economy performance in comparison with the previous two, as shown in following figures.

HWFET, speed profiles showed in Fig. 8 (a), is a high speed cruising testing cycle, thus, required torque is usually small except some accelerating sections. With the smallest available gear ratio and continuously varying ability, simplified CVT help motor run at relative higher torque and lower speed region, presented in Fig. 8 (b), comparing with SR based motor. The performance of two speeds based motor in HWFET is better than SR based motor as well, thanks to a smaller fixed ratio in $2^{\text {nd }}$ gear.

361 LA92, speed profiles presented in Fig, 11 (c), is a very aggressive driving cycle with higher speed, higher acceleration, fewer stops per $\mathrm{km}$ and less idle time. Two speeds DCT and simplified CVT based motor can achieve a higher efficiency, shown in Fig. 8 (d), by reducing speed and increase output torque using a relatively smaller gear ratio.

In contrast to previous two cycles, ECE is a low speed, low load and frequent startstop city testing cycle, which is presented in Fig. 8 (e). The multi-speed transmission does not show a significant advantage comparing to SR based motor as minimal gear changes are performed.

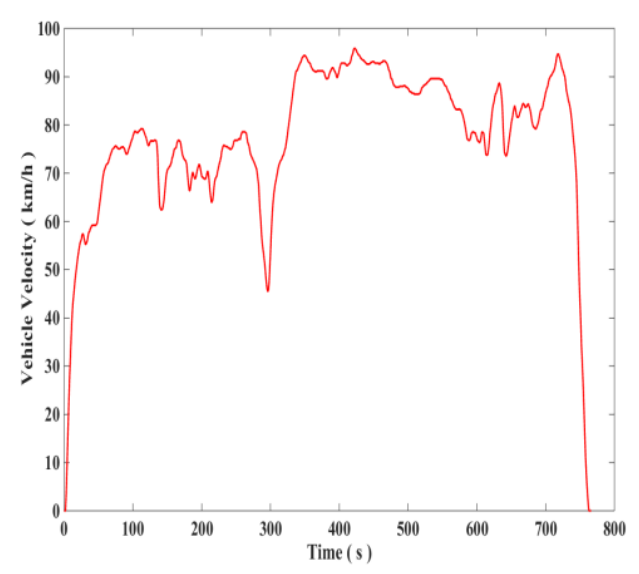

( a ) HWFET profile

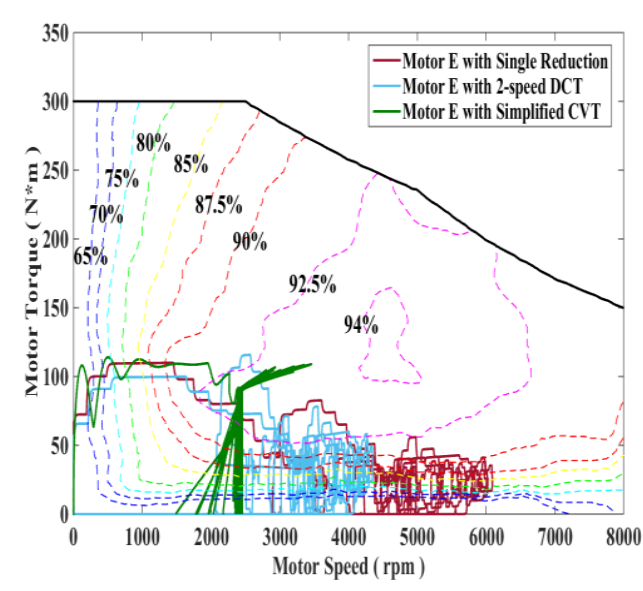

( b ) Motor operating points in HWFET 


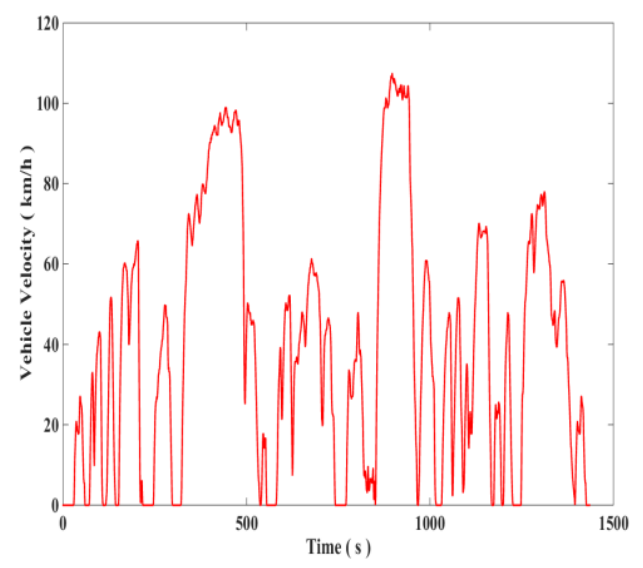

( c ) LA-92 profile

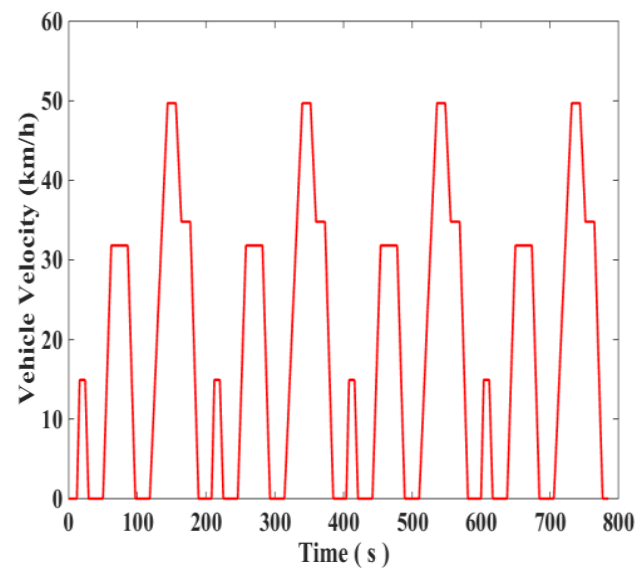

(e ) 4 x ECE profile

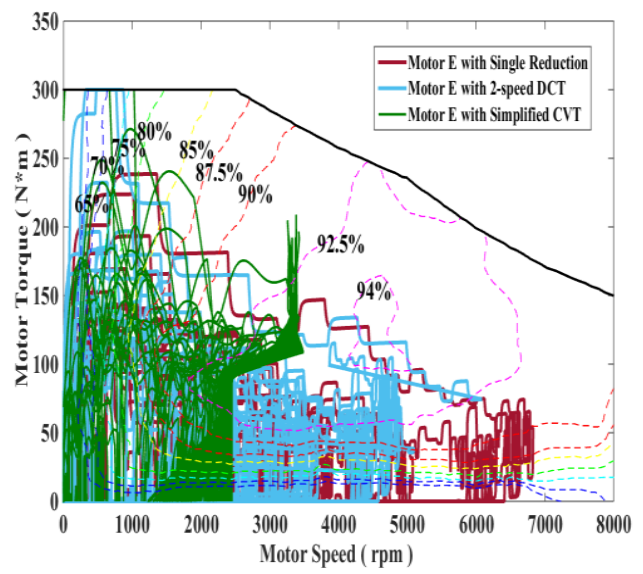

( d ) Motor operating points in LA-92

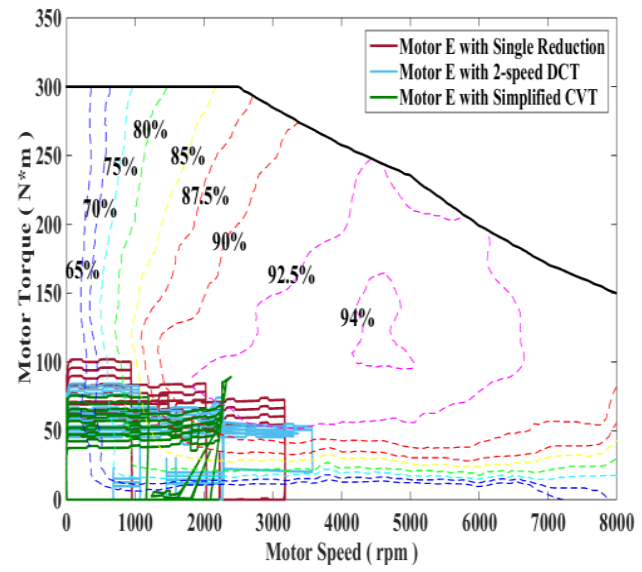

(f) Motor operating points in ECE

Figure 8: Motor operating tracks in efficiency map of BEVs with three different transmission scenarios

The details of average motor efficiency and energy consumed, in term of state of charge (SOC), in each testing cycle are demonstrated in Fig. 9 \& 11. According to the simulation results, CVT improve motor efficiency by 5\%-16\%and reduce power consumption 6\%-10\%, compared to the BEVs equipped with SR transmission system. Less improvement achieved in two speeds DCT scenario with raising motor efficiency $2 \%-10 \%$.

With a continuously variable transmission ratio, CVT based motor has the highest operation efficiency, which is followed by 2 -speed DCT based motor, then, single reduction based motor. However, this advantage is offset and transcended by 2 -speed DCT based powertrain, in term of overall energy consuming, because more energy is wasted in CVT itself. 


\section{Average Motor Efficiency}

$\square$ BEV with Single Reduction $\square$ BEV with 2-speed DCT $\square$ BEV with Simplified CVT

\section{$88.88 \%$}

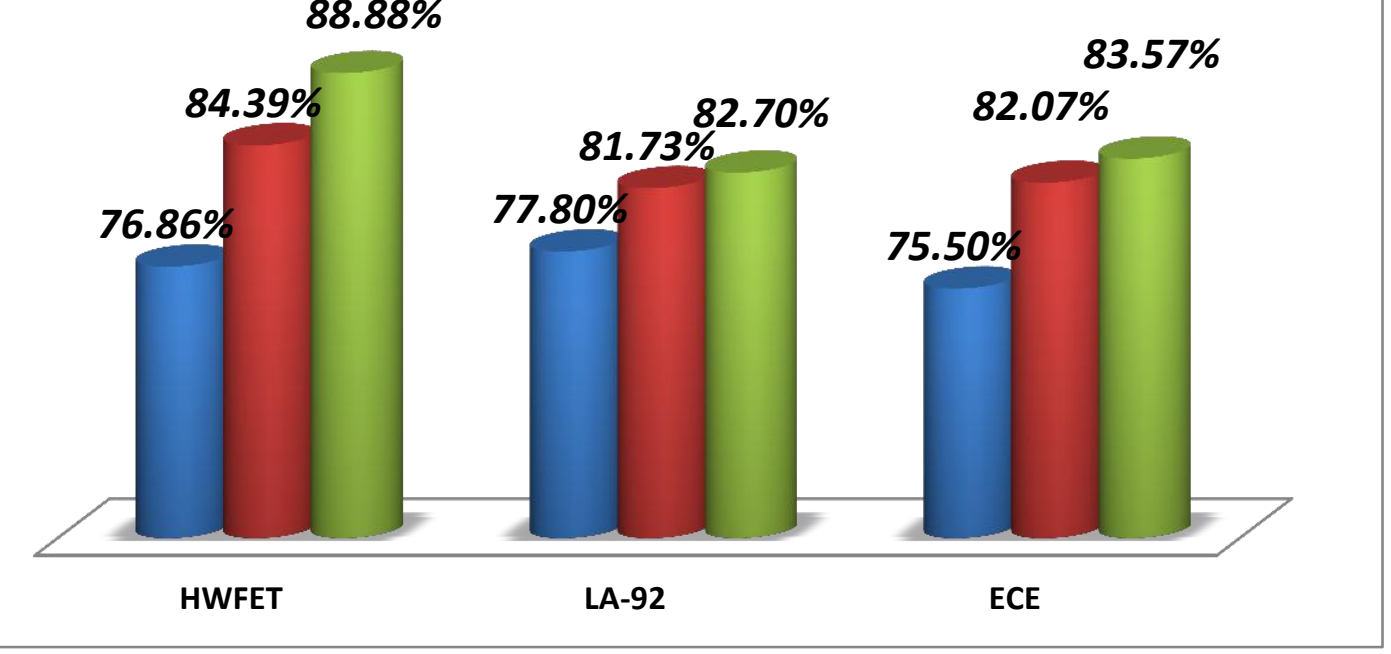

Figure 9: Average motor efficiencies for different driving cycles

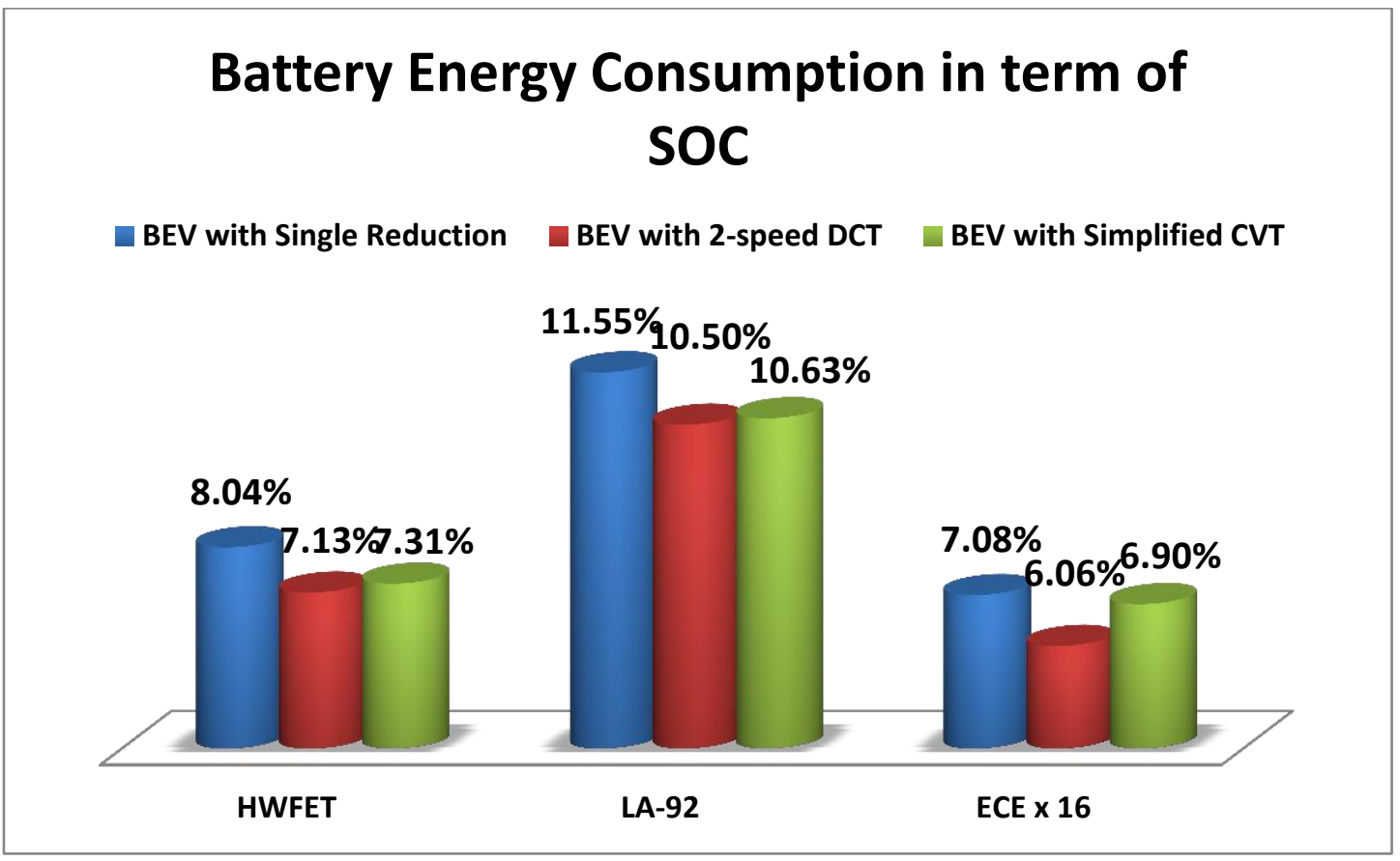

Figure 10: Energy consumed in battery for different driving cycles

\subsection{Dynamic Performance}

The dynamic performance of different transmission system based BEVs are shown in table 6. Same acceleration time is achieved in SR and two speeds DCT based BEV with the same highest gear ratio. A higher upper ratio limit helps the CVT based BEV improve the acceleration time by one second. For the same reason, the maximum driving grade is improved by $25 \%$ in CVT based BEV. The $2^{\text {nd }}$ gear of two speeds DCT helps boost top speed $57 \%$ from $112 \mathrm{~km} / \mathrm{h}$ to $176 \mathrm{~km} / \mathrm{h}$ comparing with SR BEV. 
Although the lowest ratio in CVT is less than half of that in DCT, the top speed is limited to $181 \mathrm{~km} / \mathrm{h}$ are a consequence of limited motor power. This implies that the CVT ratios could be further optimised and may improve results.

Table 7: Dynamic performance of different transmission system based BEVs

\begin{tabular}{|c|c|c|c|c|}
\hline Transmission Type & Top Speed & $0-100 \mathrm{~km} / \mathrm{h}$ Acc & $0-60 \mathrm{~km} / \mathrm{h}$ Acc & Max Grade \\
\hline SR & $112 \mathrm{~km} / \mathrm{h}$ & $14.4 \mathrm{~s}$ & $7.3 \mathrm{~s}$ & $48 \%$ \\
\hline Two Speeds DCT & $176 \mathrm{~km} / \mathrm{h}$ & $14.4 \mathrm{~s}$ & $7.3 \mathrm{~s}$ & $48 \%$ \\
\hline Simplified CVT & $181 \mathrm{~km} / \mathrm{h}$ & $13.4 \mathrm{~s}$ & $6.3 \mathrm{~s}$ & $60 \%$ \\
\hline
\end{tabular}

\section{Experiment Results}

The powertrain-testing bench consists of high voltage power, BLDC motor and controller, differential integrated two speeds DCT, wheels, flywheels and dynamometer. According to the requirement of whole system, the 4 flywheels are designed to simulate the inertia of a vehicle with a mass of $1500 \mathrm{~kg}$. The dynamometer is used to supply aerodynamic drag and rolling resistances. Fig. $11 \& 12$ demonstrate the structure and components of the powertrain-testing rig. In this experiment, HWFET and ECE cycles are selected to make up a combined driving cycle to simulate consumers' daily driving conditions. The performance of CVT on BEVs has not been experimentally verified due to the limited experimental resources. Nevertheless, the consistency of simulation and experiment results of the SR and two speeds DCT testing is very good. However, the analysis of the CVT results needs further experimental verification.

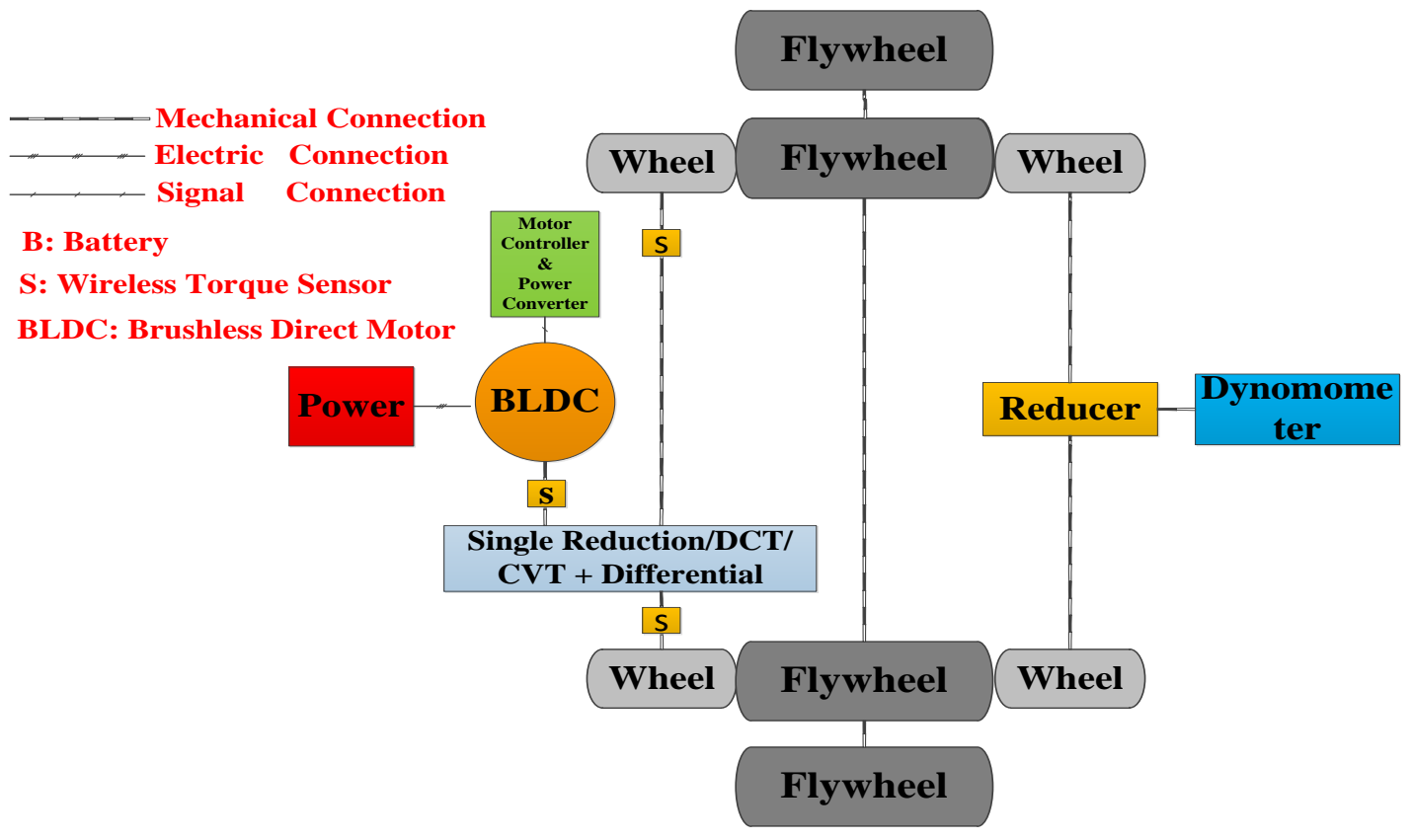

Figure 11: Experimental equipment structure sketch 


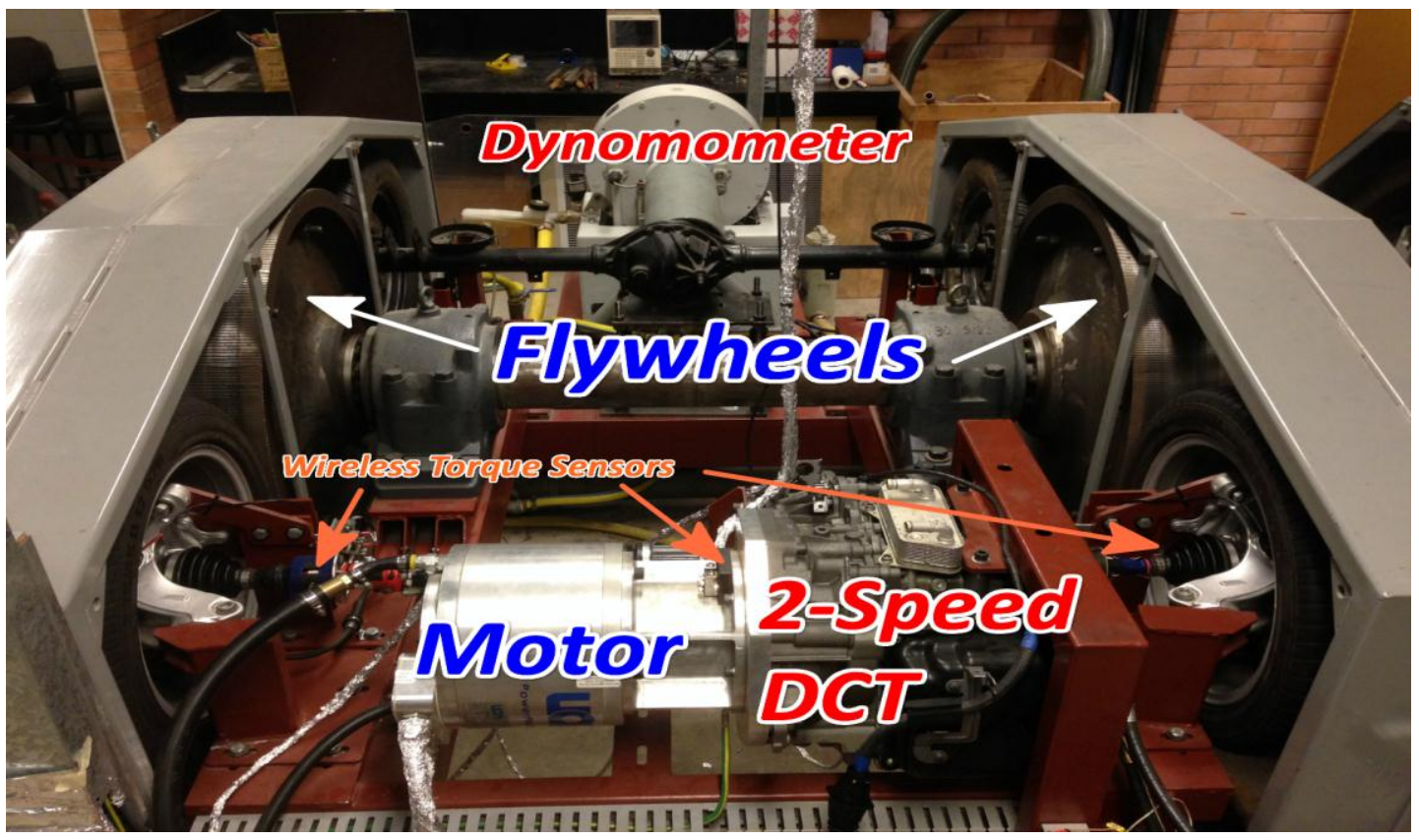

Figure 12: Plan view of testing bench

\subsection{HWFET Testing}

424 Eq.4 is used to calculate motor efficiency when propeling:

$$
\text { Motor__ }_{\text {experiment }}=\frac{\text { Torque }_{\text {out }} \times \operatorname{Speed}_{\text {motor }}(r p m) / 9550}{\text { Voltage }_{\text {in }} \times \text { Current }_{\text {in }} / 1000} \times 100 \%
$$

During regenerative braking, however, the equation is inverted as power is now fed from the powertrain to the motor and mechanical energy is converted to electric. As pridicted in simulations, a relative small ratio in higher gear will reduce motor speed and increase motor output torque at particular speed and torque demand on wheels. In other words, it leads motor to run in a higher efficiency area after the shifting from $1^{\text {st }}$ to $2^{\text {nd }}$ gear, shown in Fig.13 (a). A significant motor efficiency difference between the two models is demonstrated by Fig.13 (b-c). With $77.3 \%$ and $83.0 \%$ efficiency in SR and two speeds DCT based motor respectively, $7.4 \%$ average motor efficiency improvement is achieved. During this transition period as current approaches zero and moves to the negative current quadrant a lag between torque sensor and voltage/current sensors results erronious efficiency calculations efficiency. These results must be ignored. 


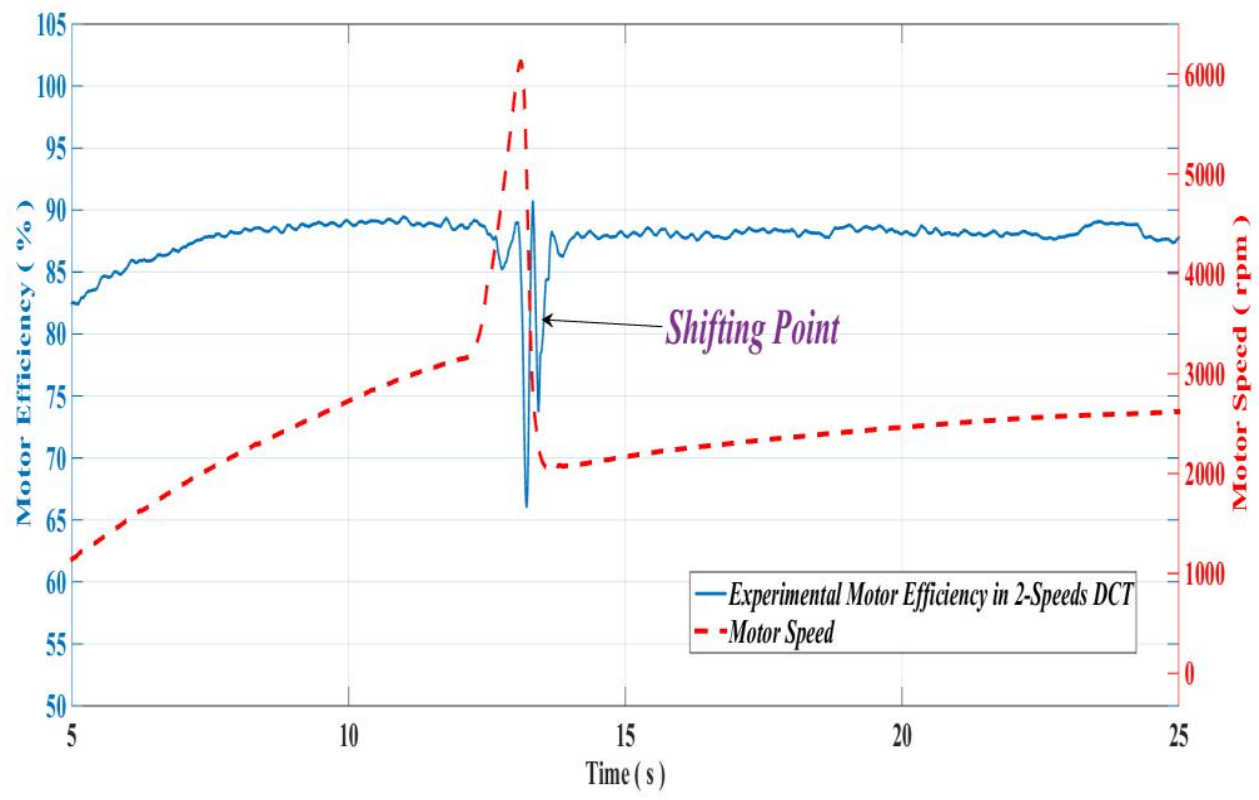

( a ) Motor efficiency varying around shifting point in two speeds DCT

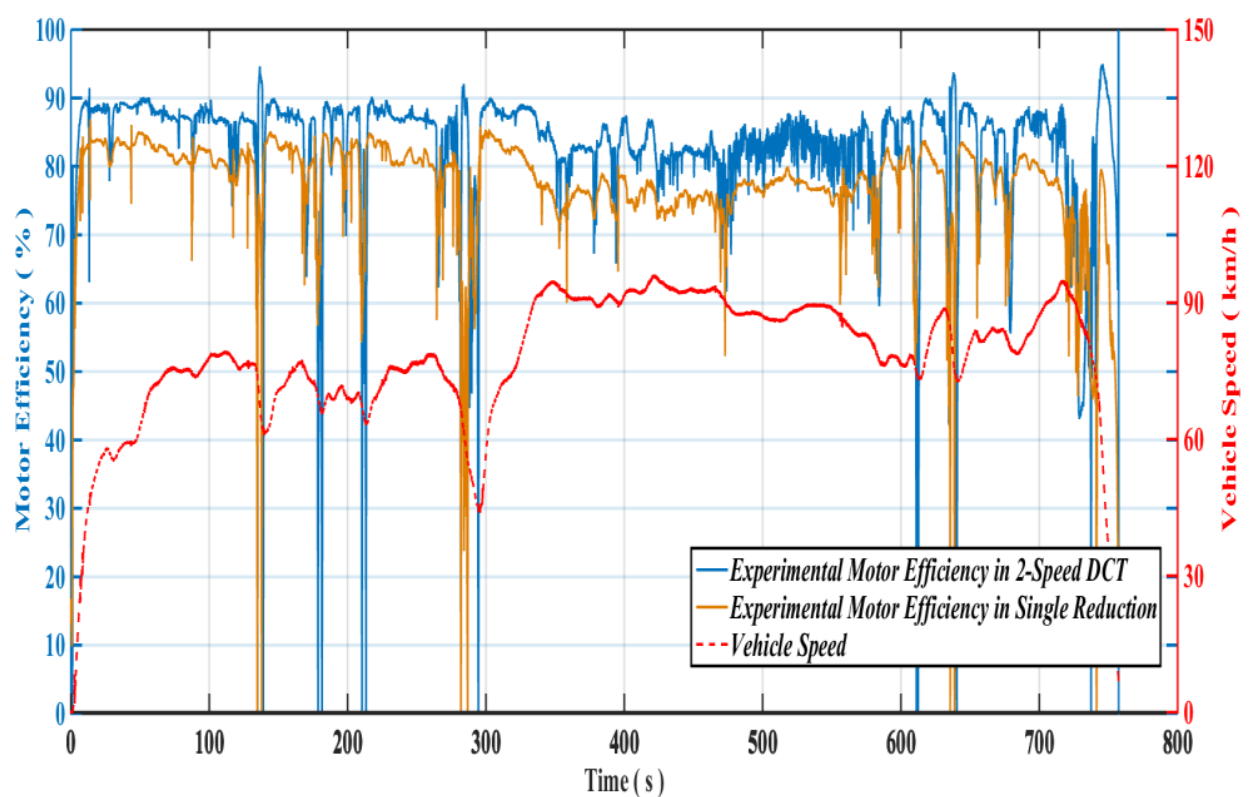

( b ) Efficiency comparison of SR and two speeds DCT based motor in HWFET 


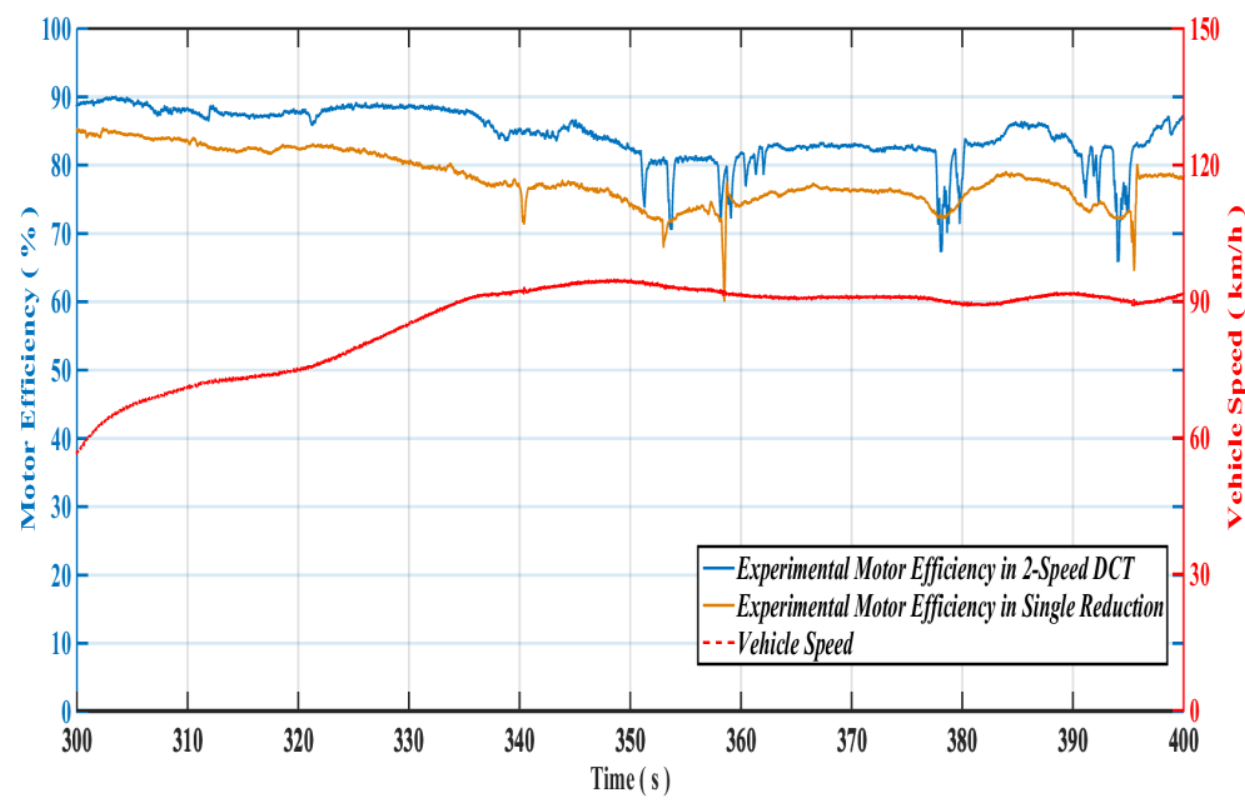

( c ) Detailed view of motor efficiency gap between SR and DCT based motors

443 Figure 13: Experimental results of SR and two speeds DCT scenarios in HWFET

444 Eq.5 is used to calculate SOC in simulation and experimental results analysing:

$$
\text { SOC }=\frac{\int_{0}^{\text {time }(s)} \operatorname{current}(A)}{3600 \times \text { Capacity }_{\text {motor }}(A h)} \times 100 \%
$$

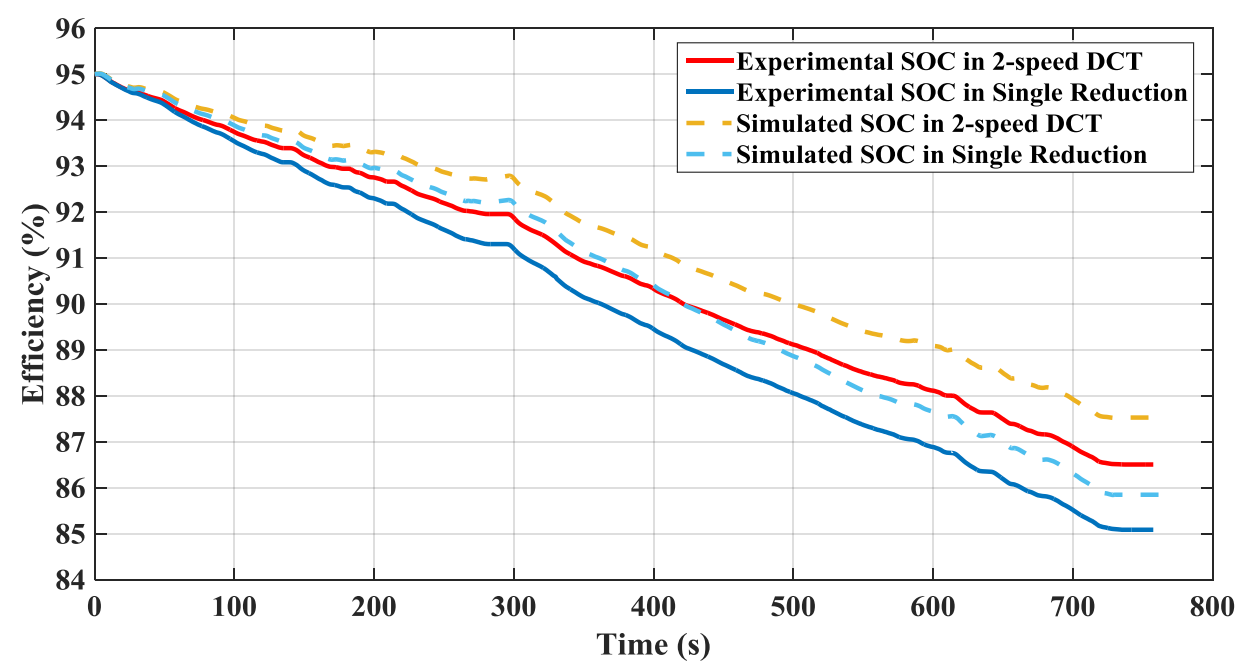

448 Comparing to the $9.9 \%$ SOC consumption in SR based BEV testing bench, two speeds DCT help save more $14.14 \%$ battery energy by only consuming $8.5 \%$ SOC in one HWFET cycle. Differences between simulation and experimental reults can be 
put down to (1) using a linear loss model for the transmissions, (2) variations in motor and inverter drive temperatures as well as transmission temperatures resulting in variance of simulated and actual losses, and (3) variation in PID vehicle control strategies reulting in different demand requlrements for simulations and experimental resuults.

\subsection{ECE Testing}

457

459

460

461

462

463

464

Comparing to the HWFET, ECE is a urban traffic oriented testing cycle. Most of the testing are acceleration and braking at a low speed. Therefore, the $2^{\text {nd }}$ gear of two speeds DCT has far less use in the ECE cycle as compared to other cycles. This has a role to play in influencing ther overall motor efficiency. The average motor efficiency is $82 \%, 5.6 \%$ higher than that of SR scenario. The improvement is slight lower than that in HWFET. Fig. 15 (a-c) presents motor efficiency varying around shifting point, whole range and partial motor efficiencies of SR and two speeds DCT based motor in ECE testing cycles repestively.

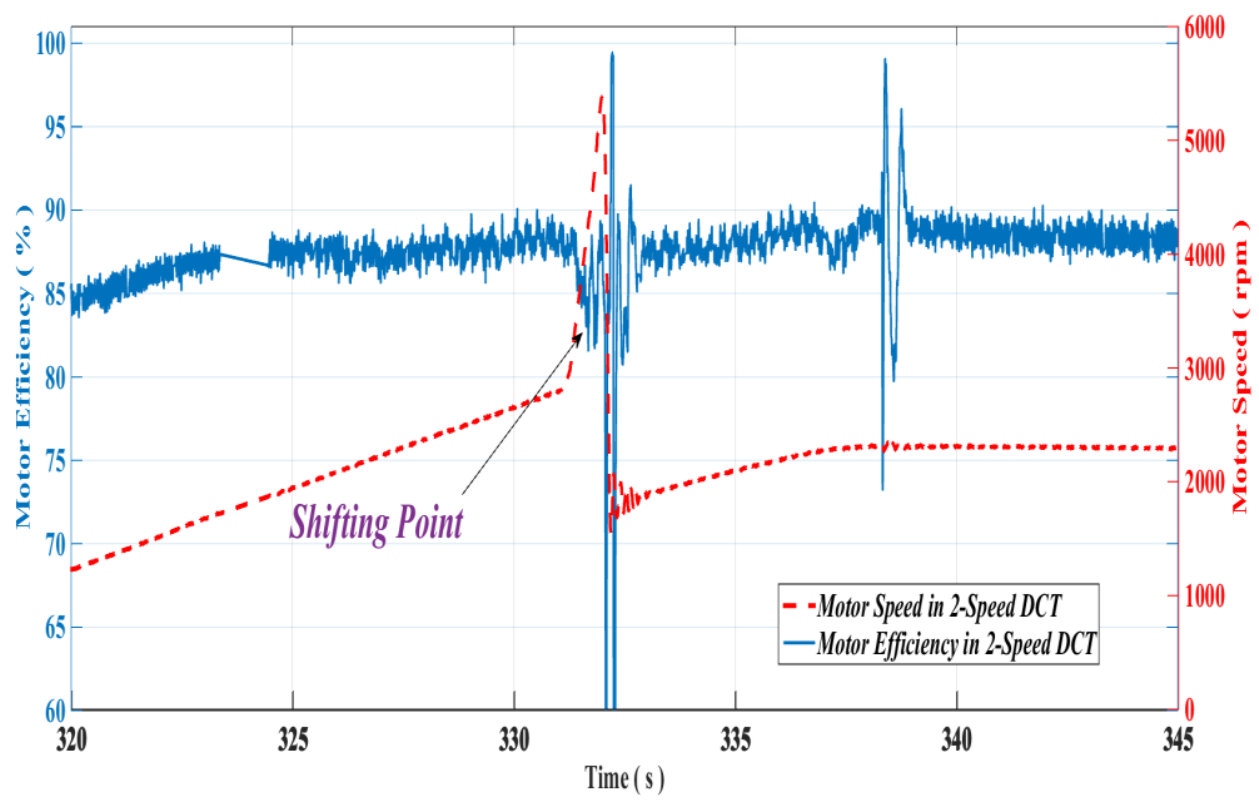

(a ) Motor efficiency varying around shifting point in two speeds DCT 


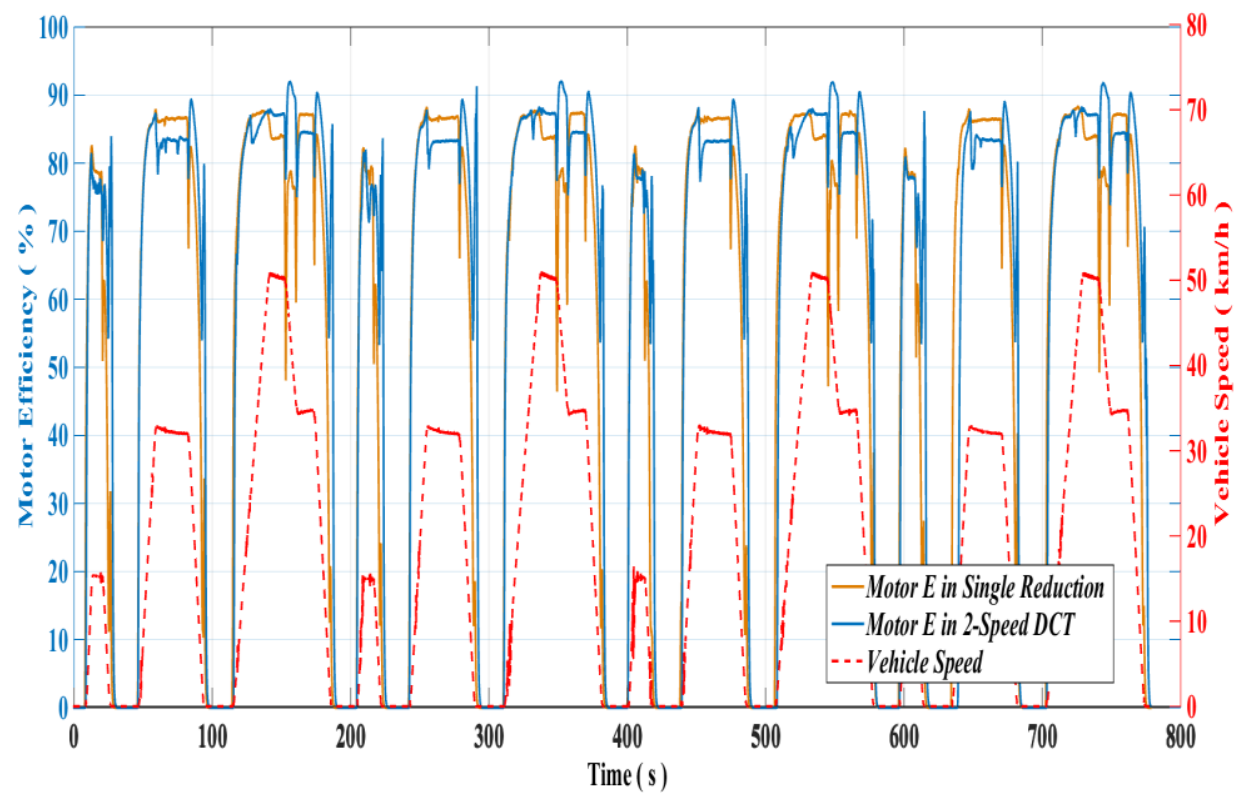

468 ( b ) Efficiency comparison of SR and two speeds DCT based motor in 4 ECE cycles

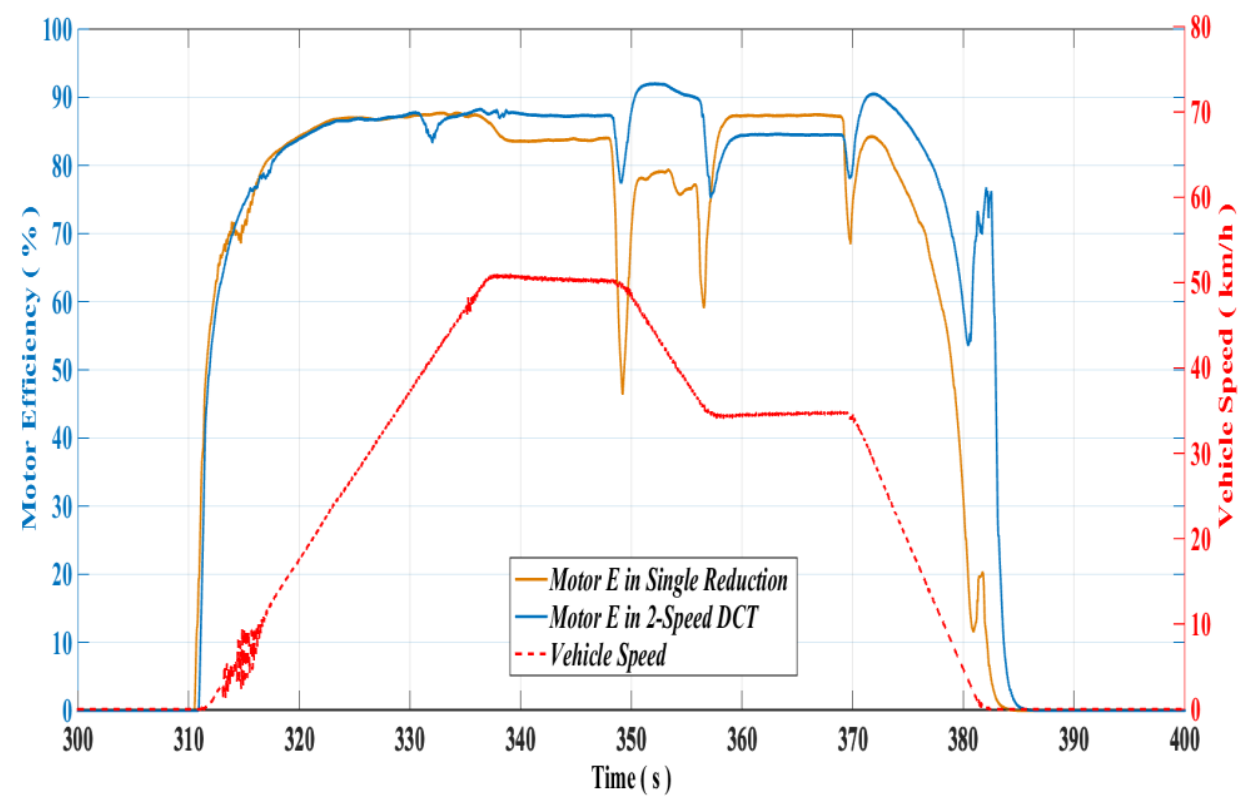

( c ) Detailed view of motor efficiency gap between SR and DCT based motors

Figure 15: Experimental results of SR and two speeds DCT model in ECE

Additional 2.6\% SOC is saved in experiment by two speeds DCT in four ECE cycles compared to SR based BEV. The experimental results is consistent with the predictions in previous simulation in battery energy consuming tendency, although a reasonable difference exist due to the mechanical loss, which is demonstrated in HWFET testing section. 


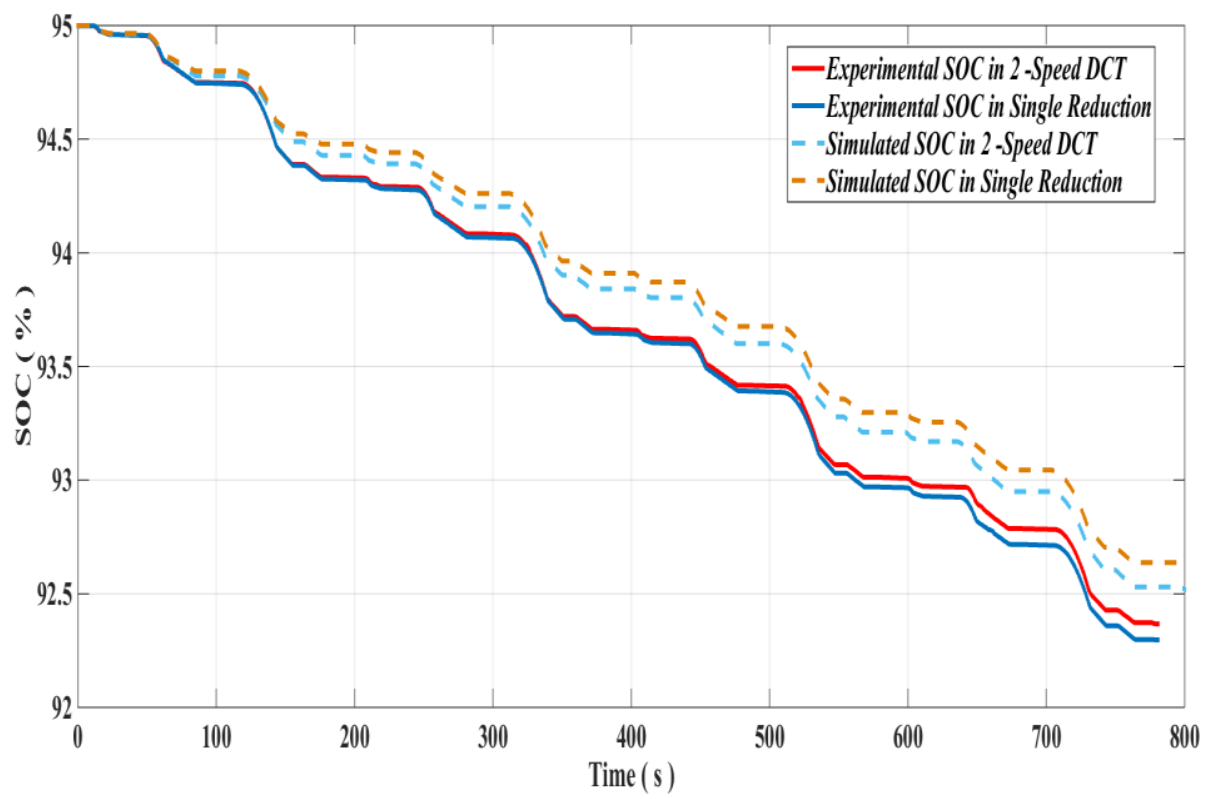

Figure 16: SOC consumption in four ECE cycles

479 Fig. 17 \& 18 clearly show the significant improvement achieved in motor efficiency and battery energy saving by multi-speed transmission systems. As shown, two speeds DCT is more efficient for highway cruising due to an alternative smaller ratio. The experimental results match the prediction in modelling simulation very well. Therefore, the ratio of experimental and simulation results, in 2-speed DCT studying, is applied to CVT scenario to attain a reasonable assuming experimental result. The outcomes therefore suggest that use of a two speeds transmission or CVT can result in a significant improvement in the overall driving range of BEVs.

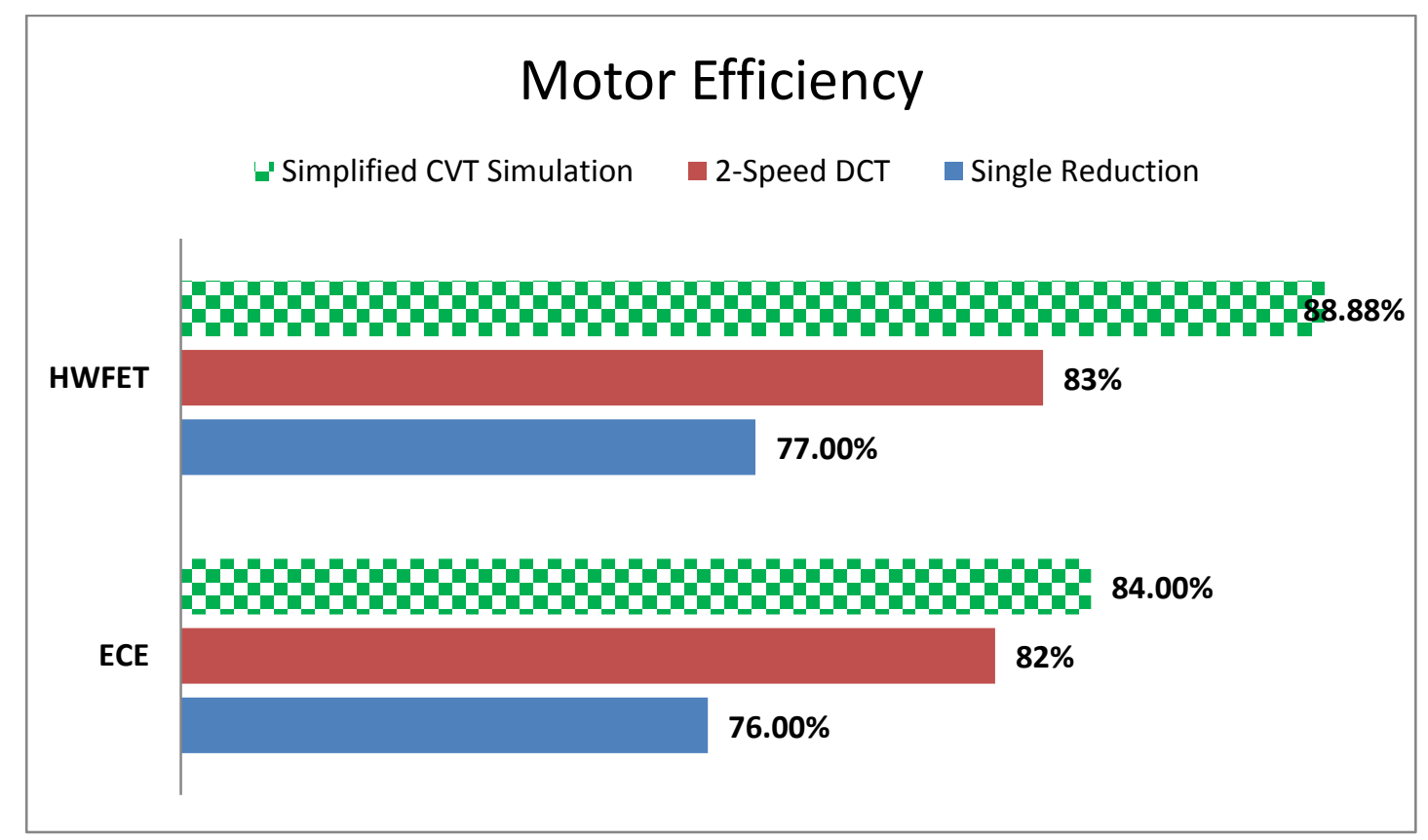

488 Figure 17: Motor efficiency comparison of BEVs equipped with different powertrains 


\section{Battery Energy Consumption in term of SOC}

Simplified CVT Simulation $\quad$ 2-Speed DCT Single Reduction

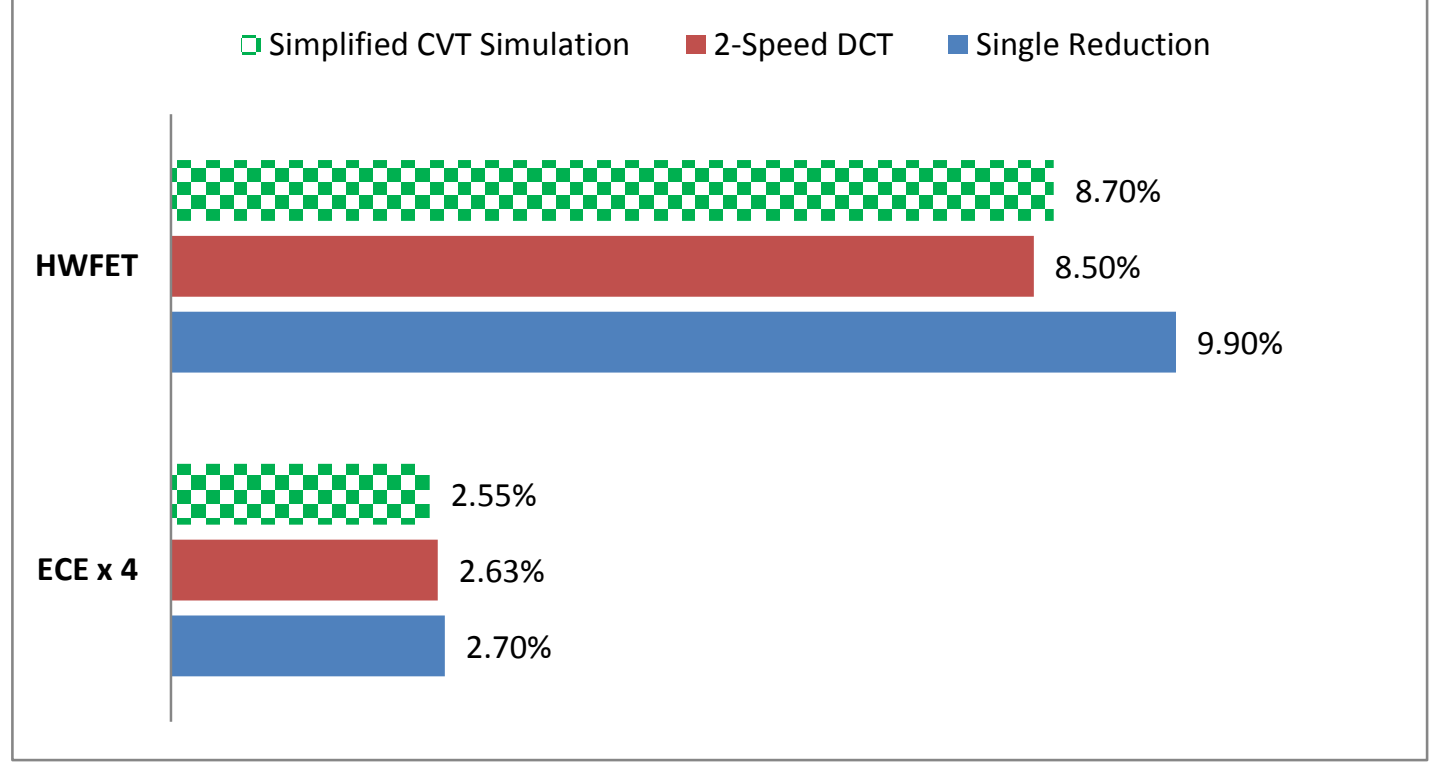

Figure 18: Comparison of power consumption in term of SOC

The total distance of one ECE and HWFET cycle are around $1 \mathrm{~km}$ and $16.5 \mathrm{~km}$ respectively. Based on the motor capacity selected in section 4 , table 8 presents the energy economy performance of different transmissions based BEVs in an easier understanding way, which is similar to the evaluation of gasoline vehicles:

Table 8: Economy performance comparison of BEVs in the term of driving Kilometre per Kwh (KPK)

\begin{tabular}{|c|c|c|c|}
\hline $\begin{array}{c}\text { Energy } \\
\text { Consumption (KPK) }\end{array}$ & SR based BEV & $\begin{array}{c}\text { Two Speeds DCT } \\
\text { based BEV }\end{array}$ & $\begin{array}{c}\text { Simplified CVT } \\
\text { based BEV }\end{array}$ \\
\hline HWFET & 6.09 & 7.09 & 6.93 \\
\hline ECE & 5.41 & 5.56 & 5.73 \\
\hline
\end{tabular}

\section{Initial Manufacturing and maintains cost analysis}

Despite the potential of long-term savings to consumers, the initial cost of BEVs presents a major market barrier to their widespread commercialization. To identify and evaluate the value of adding multi-speed transmission to BEVs, the increased manufacturing cost and reduced daily-use cost for three transmissions based BEVs are analysed and presented below.

According to the method of "design using characteristic values [28], the transmission relative selling price (RSP) can be related to the input torque $T_{1}$, the maximum ratio $i_{G, \max }$, and the number of gears $z$, shown in Eq.6. 


$$
R S P=0.0183 \times\left(i_{G, \max } \times T_{1}\right)^{0.512} z^{0.256}
$$

\begin{tabular}{|c|c|c|c|c|}
\hline Type & $z=6, i_{G, \max }=5.5$ & SR & $\begin{array}{c}\text { Two speeds } \\
\text { DCT }\end{array}$ & Simplified CVT \\
\hline RSP & 1 & 0.5 & 0.6 & 0.86 \\
\hline
\end{tabular}

In this paper, the input torque $T_{1}$ equals motor maximum output torque---300 $\mathrm{Nm}$. $i_{G, \max }$ could be found in table 4 . (*The selling price of belt CVT is estimated to be similar with a 6-Speed Automatic Transmission [29]). Thus, the estimated gearbox relative selling price (RSP) are presented in table 9

513 Combined fuel economy performance testing cycle, which is calculated by 514 harmonically averaging the city and highway fuel economies with weightings of 43 515 percent and 57 percent respectively [30], is used to determine vehicle average fuel economy in this paper. After transformation of the original formula in reference, the economy performance in combined range is:

$$
\text { Combine }_{K P K}=\frac{1}{0.57 / H W F E T_{K P K}+0.43 / E C E_{K P K}}
$$

518

519

520

Based on the experiment results in table 8 and equation (15), SR, two speeds DCT and simplified CVT based BEVs can run $5.78 \mathrm{~km}, 6.34 \mathrm{~km}$ and $6.36 \mathrm{~km}$ in combined cycles by consuming $1 \mathrm{Kw}$ electricity respectively.

$$
\text { Range }_{S R}=\text { Batter }_{\text {Capacity }} \text { Combine }_{S R_{-} K P K}=380 \times \frac{72}{1000} \times 5.78=158 \mathrm{~km}
$$

Similarly, the driving ranges for other two BEVs equipped with multi-speed transmissions are shown in table 11. Based on the same target performance in table 1, $158 \mathrm{~km}$ driving range per charge, the required battery capacity are presented in table 10 as well, comparing to the $72 \mathrm{Ah}(380 \mathrm{~V})$ battery in SR BEV.

$$
C_{\text {capacity_SR }}=72 \times 380 / 1000=27.36 \mathrm{Kwh}
$$

Table 10: Required Motor Capacity of different powertrains based BEVs

\begin{tabular}{|l|l|c|c|}
\hline SR based BEV & $\begin{array}{c}\text { Two Speeds DCT } \\
\text { based BEV }\end{array}$ & $\begin{array}{c}\text { Simplified CVT } \\
\text { based BEV }\end{array}$ \\
\hline
\end{tabular}




\begin{tabular}{|c|c|c|c|}
\hline $\begin{array}{c}\text { Driving Range for } 27.36 \\
\text { Kwh Battery }\end{array}$ & $158 \mathrm{~km}$ & $173 \mathrm{~km}$ & $174 \mathrm{~km}$ \\
\hline $\begin{array}{c}\text { Required Motor Capacity } \\
\text { for } 158 \mathrm{~km} \text { Driving Range }\end{array}$ & $27.36 \mathrm{Kwh}$ & $24.92 \mathrm{Kwh}$ & $24.84 \mathrm{Kwh}$ \\
\hline
\end{tabular}

If the estimated vehicle lifetime mileage is $300000 \mathrm{~km} \mathrm{[31]} \mathrm{and} \mathrm{the} \mathrm{efficiency} \mathrm{of}$ charger is $81 \%$ at Level 2 standard charging voltage [32], as a result of same $90 \%$ efficiency for both plug-in charger and lithium-ion battery charge/discharge [33]. The total electricity consumed in $300000 \mathrm{~km}$ is presented as:

$$
E_{S_{-} \text {lifetime }}=27.36 * 300000 / 158 / 0.81=64135(\mathrm{kWh})
$$

$$
E_{D C T_{-} \text {lifetime }}=24.92 * 300000 / 158 / 0.81=58415(\mathrm{kWh})
$$

$$
E_{C V T_{\_} \text {lifetime }}=24.84 * 300000 / 158 / 0.81=58228(\mathrm{kWh})
$$

According to OAK Ridge National Laboratory [34] and some commercial technical reports [35-37], the basis for battery electric vehicle cost calculations are shown in

\begin{tabular}{|c|c|}
\hline Vehicle Component & Cost (US \$) \\
\hline Battery Manufacturing & $\$ 400 / \mathrm{kWh}$ \\
\hline BMS, Power Electronic, etc.* & \$ 238/kWh \\
\hline Battery Pack Final Cost (Incl. Margin and Warranty) & $\$ 800 /$ Kwh \\
\hline Motor & $\$ 40 / \mathbf{k w}$ \\
\hline Transmission & \$ 12.5/kw (Motor Power) \\
\hline Average Electricity Fee ( In Australia ) [38] & $\$ 0.3 / \mathbf{k W h}$ \\
\hline
\end{tabular}
the table 11:

Table 11: Basic parts manufacturing cost of BEV

*This part includes battery management system (BMS), power electronics, connections, cell support, housing and temperature control.

540 Considering the SR and two speeds DCT are not available on the market, simplified CVT is more specifically suited to setting the benchmark price by using the method in table 11. Then, the price of two speeds DCT can be achieved by RSP in table 9. However, SR is more like the main reducer in multi-speed transmissions than a really transmission. The estimated price for SR by using RSP is too expensive. Therefore, SR's price is reduced to zero in this paper to testify if the two speeds DCT, or simplified CVT, has the ability to make up the cost disadvantage through saving battery energy. 
Comparing to ICEs, electrical components such as traction motors and controllers require little maintenance. For instance, motor brake (regenerative brake) largely reduces the frequency of brake pedal replacement. The estimated maintenance costs for BEVs are around 70\% [39] of an equivalent ICE vehicle, with a cost of $\$ 4.1$ cents per $\mathrm{km}$ for a medium passenger BEV. According to [36], no battery replacement is expected before $375000 \mathrm{~km}$ distance in theoretically, at least $250000 \mathrm{~km}$ in practice. Therefore, in this paper, no battery replacement fee is applied to lifetime final cost for consumers. Considering the only different in this study for three structures is the gearbox, the lifetime vehicle maintenance cost is estimated to be the same, because the required maintenance for gearbox is infrequent, usually every $100000 \mathrm{~km}$ for transmission oil change, comparing to the frequency of changing tyres, brake, electronics and regular inspection. It only shares very small part of the whole maintenance cost. Furthermore, some manufacturers guarantee their CVT products do not need any maintenance anymore [40].

All powertrain components received a manufacturer's mark-up of 50\% in addition to a dealer's mark-up of $16.3 \%$ [34]. The final post-retail selling price on the market will be approximately 1.7 times [41] as the pre-retail price calculated by data in table 11 , except the final battery pack retail price.

The required battery capacity is reduced due to the relative less energy consumed by two speeds DCT and CVT based BEV in particular testing cycles. Refer to the target performance and vehicle specifications listed in the tables $1 \& 2$, the manufacturing and daily-use cost of SR, two speeds DCT and simplified CVT (Simulation) based BEVs are presented in the tables 12. Again, it must be stressed that all the CVT relevant data is based on the simulation result. It still needs further experiment validation.

Table 12: Manufacturing Cost, Recommended Retail Price and Maintenance Cost

\begin{tabular}{|c|c|c|c|}
\hline $\begin{array}{c}\text { Vehicle Component Cost } \\
\text { (\$ USD) }\end{array}$ & SR based BEV & $\begin{array}{c}\text { Two speeds DCT } \\
\text { based BEV }\end{array}$ & $\begin{array}{c}\text { Simplified CVT } \\
\text { based BEV }\end{array}$ \\
\hline Battery Manufacturing & $\mathbf{\$ 1 0 9 4 4}$ & $\mathbf{\$ 9 9 6 8}$ & $\mathbf{\$ 9 9 3 6}$ \\
\hline BMS, Power Electronic, etc. & $\mathbf{\$ 6 5 1 2}$ & $\mathbf{\$ 5 9 3 1}$ & $\mathbf{\$ 5 9 1 2}$ \\
\hline $\begin{array}{c}\text { Battery Pack Final Cost } \\
\text { (Incl. Margin and Warranty) }\end{array}$ & $\mathbf{\$ 2 1 8 8 8}$ & $\mathbf{\$ 1 9 9 3 6}$ & $\mathbf{\$ 1 9 8 7 2}$ \\
\hline $\begin{array}{c}\text { Transmission (125 kw) } \\
\text { Motor }\end{array}$ & $\mathbf{\$ 0}$ & $\mathbf{\$ 1 0 9 0}$ & $\mathbf{\$ 1 5 6 2}$ \\
\hline $\begin{array}{c}\text { Total Powertrain Pre-Retail } \\
\text { (1.7 retail makeup apply to } \\
\text { motor and transmission) }\end{array}$ & $\mathbf{\$ 2 6 8 8 8}$ & $\mathbf{\$ 2 6 0 2 6}$ & $\mathbf{\$ 2 6 4 3 4}$ \\
\hline
\end{tabular}




\begin{tabular}{|c|c|c|c|}
\hline Glider [41] & $\mathbf{\$ 1 7 3 1 4}$ & $\mathbf{\$ 1 7 3 1 4}$ & $\mathbf{\$ 1 7 3 1 4}$ \\
\hline Recommended Retail Price & $\$ 47702$ & $\$ 47603$ & $\$ 48341$ \\
\hline $\begin{array}{c}\text { Vehicle Maintenance Cost } \\
(300000 \mathrm{~km})\end{array}$ & $\mathbf{\$ 1 2 3 0 0}$ & $\mathbf{\$ 1 2 3 0 0}$ & $\mathbf{\$ 1 2 3 0 0}$ \\
\hline $\begin{array}{c}\text { Battery Replacement Cost } \\
\text { Electricity Cost in lifetime }\end{array}$ & $\mathbf{\$ 1 9 2 4 1}$ & $\mathbf{\$ 1 7 5 2 5}$ & $\mathbf{\$ 1 7 4 6 8}$ \\
\hline Total Balance & $\$ \mathbf{7 9 2 4 3}$ & $\$ \mathbf{7 7 4 2 8}$ & $\mathbf{\$ 7 8 1 0 9}$ \\
\hline
\end{tabular}

\section{Conclusion}

This paper proposes two redesigned multi-speed transmission systems, two speeds DCT and CVT without torque converter, as alternatives for widely used fixed ratio SR on BEVs. The structures and principles of two speeds DCT and simplified CVT are detailed to demonstrate how these can be integrated with the motor and how the traditional DCT and CVT transmissions can be simplified.

Gear ratios for different transmissions are determined to meet the performance requirements and make the most of the existing equipment. Based on the motor characteristics and the requirements of smooth shifting and energy saving, two customized shifting schedules are designed for two speeds DCT and simplified CVT. A comprehensive vehicle model is built in the Matlab/Simulink® to calculate the motor efficiency improvement and saved battery energy. Detailed comparison of simulation results among SR, two speeds DCT and simplified CVT equipped BEVs, in urban and highway testing cycles, are presented that both two speeds DCT and simplified CVT have a significant improvement on economy performance relative to single speed transmission. At the meanwhile, better dynamic performance is attained, e.g. faster acceleration time and higher top speed.

The performance of SR and two speeds DCT on BEVs is experimentally verified in an integrated powertrain testing bench in the Lab. Thanks to the additional relative smaller ratio in $2^{\text {nd }}$ gear, comparing to the SR, two speeds DCT is more likely to run at high efficiency area and consume less energy. The improvement varies depends on driving cycles. For the city cycles, e.g. ECE, frequent start-stop situations doesn't give much chance to the $2^{\text {nd }}$ gear in two speeds DCT to participate. However, the $2^{\text {nd }}$ gear plays an important role in highway situation, e.g. HWFET, $14 \%$ battery energy is saved in each cycle.

Initial manufacturing and daily-use cost is analysed to estimate whether the multispeed transmission is worthwhile for customers, considering the saved energy and increased transmission cost. The outcomes show that two-speed DCT based BEV has the lowest retail price, thanks to the minimized battery capacity requirement, though the gearbox is more expensive. Due to CVT is the most expensive one in these three candidates, the CVT based BEV cost a little bit more than SR based BEV. However, the small retail price difference obviously signalling that it is a smart choice to add a 
606 multi-speed transmission system to BEVs. At the viewpoint of lifetime long costing, 607 thousands of dollars saving is expected by minimize electricity consuming.

608 In summary, both two-speed DCT and simplified CVT not only improve BEVs' 609 dynamic performance with little additional initial cost, but also save customer's 610 money in the long term. The improvement achieved in this paper is greater than most 6112 2, 3, even 4 speeds transmissions, which were designed for BEVs, proposed in 612 previous reference, whilst offers a simple structure and acceptable price. Furthermore, 613 two-speed DCT equipped BEV save more money in the long term, but simplified 614 CVT equipped BEV can offer a better driving experience, no matter in accelerating, 615 climbing or shifting. 


\section{Acknowledgement}

618 The authors would like to thank the AutoCRC and Changzhou New Energy Vehicle 619 Research Academy for their financial support, and Australian Research Council for 620 financial support under grant DP1501\#\#\#\#. Jiageng Ruan would also like to thank the 621 Chinese Scholarship Council for financial support for his research and grateful to Prof. 622 Nong Zhang and Dr. Paul Walker for their valuable advice. 


\section{Appendices}

\section{Al Ratio design for top speed}

The maximum speed achieved in the vehicle can be used to determine the upper limit of gear ratios:

$$
V_{\text {max }}=\left(n_{\max } * 2 \pi r / 60 * 3.6\right) / i_{g}=0.377 n_{\max }(\mathrm{rpm}) r / i_{g} \gg 150(\mathrm{~km} / \mathrm{h})
$$

Substitute $V_{\text {max }}=150 \mathrm{~km} / \mathrm{h}, \quad n_{\max }=8000 \mathrm{rpm}, r=0.3125 \mathrm{~m}$ :

$$
i_{g} \leq 6.3
$$

Additionally, at the viewpoint of motor efficiency, a lower speed, e.g. 5000-6000 rpm, should be used for vehicle continuously running at $150 \mathrm{~km} / \mathrm{h}$. The required gear ratio should be lower than 6.3 .

\section{A2 Ratio design for max grade}

The vehicle should be able to drive on a particular grade road at minimum required speed, which is usually used to design the minimum gear ratio. The relationship of gear ratio and driving grade is given in Eq.A3. For low vehicle speeds, the aerodynamic drag is assumed to be zero. Considering the different efficiency of transmissions, $\eta=0.85$ is selected in this calculation for design redundancy:

$$
i_{\text {gmin }} \geq \frac{r m g\left(C_{R} \cos \varphi+\sin \varphi\right)}{T_{\text {motor-max }} \eta}=6.4
$$

\section{A3 Ratio design for acceleration time}

The acceleration time of vehicle can be expressed in Eq.A4 and Eq.A5

$$
\begin{aligned}
& a=\frac{f}{m}=\left[\frac{T_{m-\max } \eta i_{g}}{r}-\left(\operatorname{mg} C_{R} \cos \varphi+\operatorname{mg} \sin \varphi+\frac{\mathrm{C}_{\mathrm{D}} \mathrm{Au}^{2}}{21.15}+\frac{\delta \mathrm{md}_{\mathrm{u}}}{\mathrm{d}_{\mathrm{t}}}\right)\right] / m \\
& =\frac{\mathrm{d}_{u}}{\mathrm{~d}_{\mathrm{t}}}(\mathrm{A} 4) \\
& t_{0-100}=\int_{0}^{100} \frac{21.15 m r(1+\delta)}{21.15 T_{m-\max }(v) i_{g} \eta-21.15 m r g C_{R}-C_{D} A r v^{2}} d v
\end{aligned}
$$




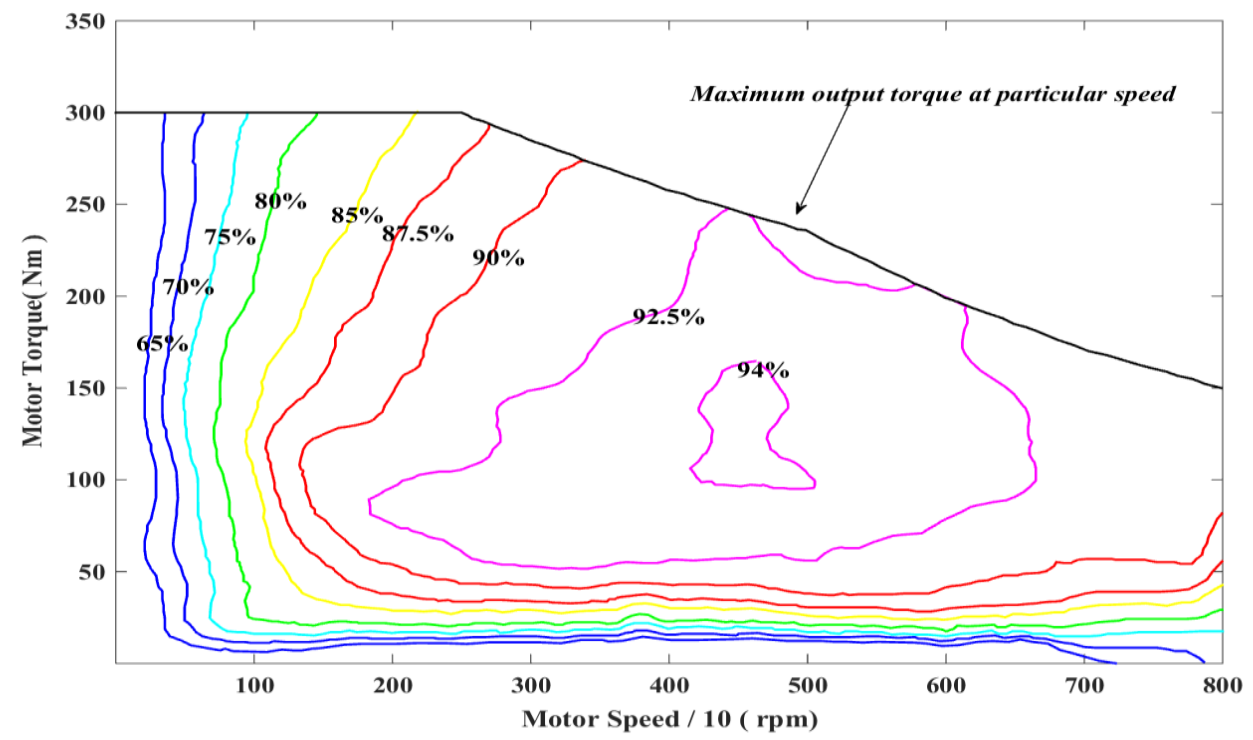

651 The maximum variable motor torque $T_{\text {motor }}$ shown in Fig.A1 is expressed as 652 following equation:

$$
T_{m-\max }(v)=\left\{\begin{array}{c}
300(n<2500 \mathrm{rpm}) \\
370-0.028 n \quad(n \gg 2500 \mathrm{rpm})
\end{array}\right.
$$

653 Thus, substitute $r=0.3125$ to (1) and rewrite Eq.A6 as:$$
\left\{\begin{array}{c}
\int_{0}^{0.1178 * 2500 / i_{g}} \frac{21.15 m r(1+\delta)}{21.15 * 300 * i_{g} \eta-21.15 m r g C_{R}-C_{D} A r v^{2}} d v(n<2500) \\
\int_{0.1178 * 2500 / i_{g}}^{100} \frac{21.15 m r(1+\delta)}{21.15\left(370-0.028 \times \frac{v \times i_{g}}{0.377 * r}\right) i_{g} \eta-21.15 m r g C_{R}-C_{D} A r v^{2}} d v(n \gg 2500)
\end{array} t_{0-100}=\right.
$$

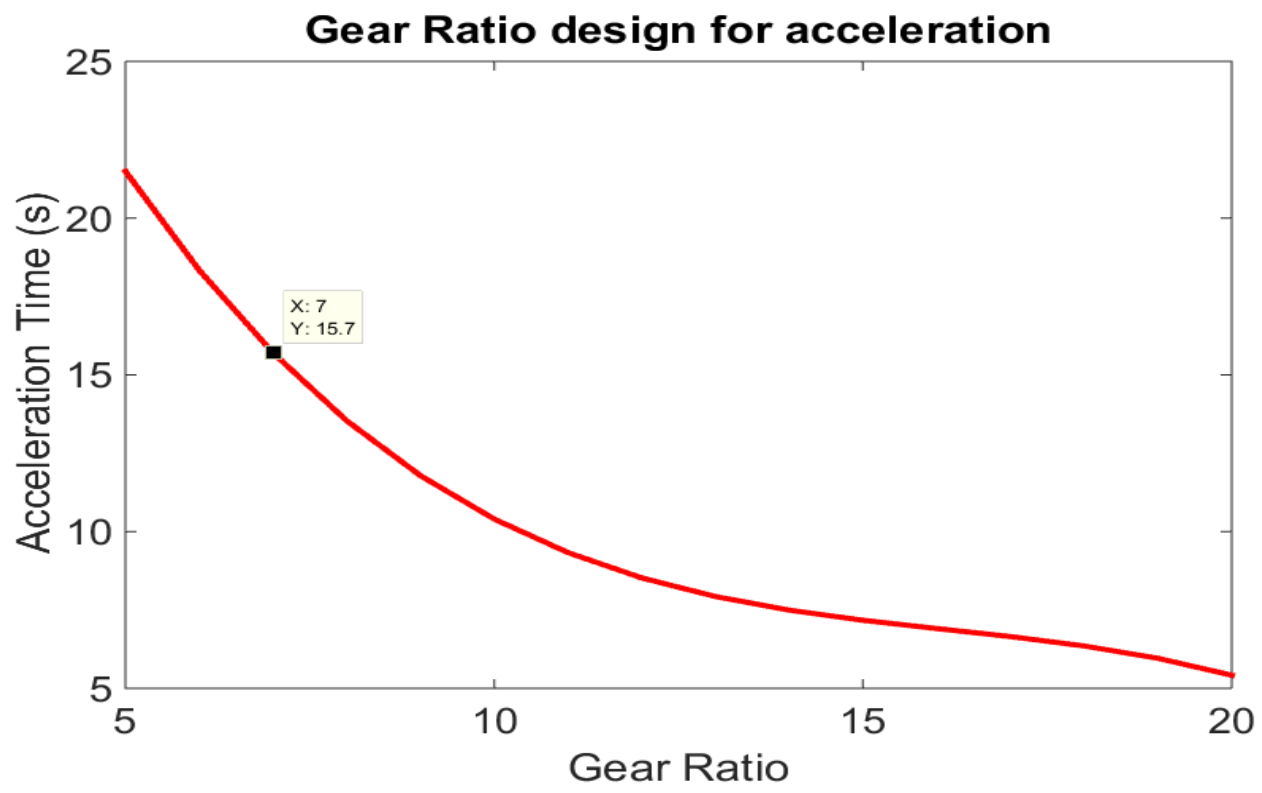


657 Figure A2 Acceleration time based on gear ratio and particular motor characteristics

658 As shown in Fig.A2, the gear ratio should be no less than 7 for a 15 s or shorter $0-100$ $659 \mathrm{~km} / \mathrm{h}$ acceleration time.

$\begin{array}{ll}i & i\end{array}$

660 


\section{Reference}

662

663

664

665

666

667

668

669

670

671

672

673

674

675

676

677

678

679

680

681

682

683

684

685

686

687

688

689

690

691

692

693

694

695

696

697

698

699

700

701
[1] Li Y, Liu M, Lau J, Zhang B. A novel method to determine the motor efficiency under variable speed operations and partial load conditions. Appl Energy 2015;144:234-40. doi:http://dx.doi.org/10.1016/j.apenergy.2015.01.064.

[2] Roberts S. Multispeed transmission for electric vehicles. ATZ Worldw 2012;114:8-11. doi:10.1007/s38311-012-0162-4.

[3] Di Nicola F, Sorniotti A, Holdstock T, Viotto F, Bertolotto S. Optimization of a Multiple-Speed Transmission for Downsizing the Motor of a Fully Electric Vehicle. SAE Int J Alt Power 2012;1:134-43. doi:10.4271/2012-01-0630.

[4] Ren Q, Crolla D a., Morris a. Effect of transmission design on Electric Vehicle (EV) performance. 5th IEEE Veh Power Propuls Conf VPPC '09 2009;4:12605. doi:10.1109/VPPC.2009.5289707.

[5] Bottiglione F, De Pinto S, Mantriota G, Sorniotti A. Energy Consumption of a Battery Electric Vehicle with Infinitely Variable Transmission. Energies 2014;7:8317-37. doi:10.3390/en7128317.

[6] Morozov A, Humphries K, Zou T, Martins S, Angeles J. Design and Optimization of a Drivetrain with Two-speed Transmission for Electric Delivery Step Van. IEEE Int. Electr. Veh. Conf. IEVC 2014, Florence, Italy, 2014.

[7] Wu G, Zhang X, Dong Z. Impacts of Two-Speed Gearbox on Electric Vehicle's Fuel Economy and Performance 2013. doi:10.4271/2013-01-0349.

[8] Jun-Qiang X, Guang-Ming X, Yan Z. Application of automatic manual transmission technology in pure electric bus. 2008 IEEE Veh Power Propuls Conf VPPC 2008 2008:5-8. doi:10.1109/VPPC.2008.4677583.

[9] Galvagno E, Velardocchia M, Vigliani a. Analysis and simulation of a torque assist automated manual transmission. Mech Syst Signal Process 2011;25:1877-86. doi:10.1016/j.ymssp.2010.12.014.

[10] R P G Heath. Seamless AMT offers efficient alternative to CVT. JSAE Annu Congr 2007:4. 
[11] Goetz M, Levesley MC, Crolla DA. Integrated Powertrain Control of Gearshifts On Twin Clutch Transmissions 2004. doi:10.4271/2004-01-1637.

[12] Zhu B, Zhang N, Walker P, Zhan W, Zhou X, Ruan J. Two-Speed DCT Electric Powertrain Shifting Control and Rig Testing. Adv Mech Eng 2013;2013:1-10. doi:10.1155/2013/323917.

[13] Roser H, Walker PD, Nong Zhang. IMECE2013-64139. Proc. ASME 2013 Int. Mech. Eng. Congr. Expo. IMECE2013, 2013, p. 1-7.

[14] Walker PD, Zhang N. Modelling of dual clutch transmission equipped powertrains for shift transient simulations. Mech Mach Theory 2013;60:47-59. doi:10.1016/j.mechmachtheory.2012.09.007.

[15] Walker PD, Roser H, Zhang N, Fang Y. Comparison of Powertrain System Configurations for Electric Passenger Vehicles 2015. doi:10.4271/2015-010052 .

[16] Simmons RA, Shaver GM, Tyner WE, Garimella S V. A benefit-cost assessment of new vehicle technologies and fuel economy in the U.S. market. Appl Energy n.d. doi:http://dx.doi.org/10.1016/j.apenergy.2015.01.068.

[17] Patel D, Ely J, Overson M. CVT Drive Research Study 2005. doi:10.4271/2005-01-1459.

[18] Srivastava N, Haque I. A review on belt and chain continuously variable transmissions (CVT): Dynamics and control. Mech Mach Theory 2009;44:1941. doi:10.1016/j.mechmachtheory.2008.06.007.

[19] Mäder KM. Continuously Variable Transmission: Benchmark, Status \& Potentials. 2005.

[20] Lee, H; Kim H. Improvement of fuel economy by shift speed control for a metal belt continuously variable. Proc Inst Mech Eng PART D J Automob Eng 2012;216:741-9.

[21] Veenhuizen P a, Bonsen B, Klaassen TWGL, Albers PHWM. Pushbelt CVT efficiency improvement potential of servo-electromechanical actuation and slip control 2004:1-7.

[22] van der Sluis F, van Dongen T, van Spijk G-J, van der velde A, van Heeswijk A. Efficiency Optimization of the Pushbelt CVT 2007. doi:10.4271/2007-01- 
[23] Saito T, Miyamoto K. Prediction of CVT Transmission Efficiency by Metal VBelt and Pulley Behavior with Feedback Control 2010. doi:10.4271/2010-010855 .

D. L. Robinette, J. M. Schweitzer, D. G. Maddock, C. L. Anderson, J. R. Blough and MAJ. Development of a Dimensionless Model for Predicting the Onset of Cavitation in Torque Converters. New Adv. Veh. Technol. Automot. Eng., 2012, p. 333-58. doi:10.5772/45793.

[27] Saito T. Transmission Efficiency Prediction of a Metal Pushing V-belt CVT with Implementation of Control Logic. SIMULIA Cust. Conf., 2010, p. 1-12.

[28] Naunheimer H, Bertsche B, Ryborz J, Novak W. Overview of the Traffic Vehicle - Transmission System. Automot. Transm. SE - 2, Springer Berlin Heidelberg; 2011, p. 28-72. doi:10.1007/978-3-642-16214-5_2.

[29] Francis van der Sluis, Noll E van der, Leeuw H de. Key Technologies of the Pushbelt CVT. Int J Automot Eng 2013;4:1-8.

[30] Berry IM. The effects of driving style and Vehicle performance on the real world fuel consumption of US light duty vehicles. Massachusetts Institute of Technology, 2010.

[31] Lu S. Vehicle Survivability and Travel Mileage Schedules. Security 2006:40.

[32] Saxena S, MacDonald J, Moura S. Charging ahead on the transition to electric vehicles with standard 120\&\#xa0;V wall outlets. Appl Energy n.d. doi:http://dx.doi.org/10.1016/j.apenergy.2015.05.005.

[33] Bi Z, Song L, De Kleine R, Mi CC, Keoleian GA. Plug-in vs. wireless charging: Life cycle energy and greenhouse gas emissions for an electric bus system. Appl Energy 2015;146:11-9. 
doi:http://dx.doi.org/10.1016/j.apenergy.2015.02.031.

[34] OAK RIDGE NATIONAL LABORATORY. Plug-in Hybrid Electric Vehicle Value Proposition Study. 2010.

790

[35] Kinghorn R, Kua D. Forecast Uptake and Economic Evaluation of Electric Vehicles in Victoria. 2011.

[36] Cluzel C, Douglas C. Cost and performance of EV batteries: Final report for The Committee on Climate Change. 2012.

[37] Newbery D, Strbac G. What is the target battery cost at which Battery Electric Vehicles are socially cost competitive? 2014.

[38] Commission AEM. ELECTRICITY PRICE TRENDS FINAL REPORT: Possible future retail electricity price movements: 1 July 2012 to 30 June 2015. Sydney: 2013.

[39] Onat NC, Kucukvar M, Tatari O. Conventional, hybrid, plug-in hybrid or electric vehicles? State-based comparative carbon and energy footprint analysis in the United States. Appl Energy 2015;150:36-49. doi:http://dx.doi.org/10.1016/j.apenergy.2015.04.001.

[40] Subaru CVT - Why you should have it and when you shouldn't. n.d. http://www.manchestersubaru.com/cvt-transmission.htm (accessed July 14, 2015).

[41] Sharma R, Manzie C, Bessede M, Brear MJ, Crawford RH. Conventional, hybrid and electric vehicles for Australian driving conditions - Part 1: Technical and financial analysis. Transp Res Part C Emerg Technol 2012;25:238-49. doi:10.1016/j.trc.2012.06.003. 